\title{
Connective Tissue Growth Factor Causes Glaucoma by Modifying the Actin Cytoskeleton of the Trabecular Meshwork
}

\author{
Benjamin Junglas, ${ }^{*}$ Sabrina Kuespert, ${ }^{*}$ \\ Amin A. Seleem, ${ }^{*}$ Tobias Struller, ${ }^{*}$ \\ Sabrina Ullmann, ${ }^{*}$ Michael Bösl, ${ }^{\dagger}$ \\ Anja Bosserhoff, ${ }^{\ddagger}$ Josef Köstler, ${ }^{\S}$ Ralf Wagner, ${ }^{\S}$ \\ Ernst R. Tamm, ${ }^{*}$ and Rudolf Fuchshofer* \\ From the Institutes of Human Anatomy and Embryology,* \\ Pathology $y^{\ddagger}$ and Medical Microbiology, University of Regensburg, \\ Regensburg; and the Max Planck Institute of Neurobiology, ${ }^{\dagger}$ \\ Martinsried, Germany
}

The most critical risk factor for optic nerve damage in cases of primary open-angle glaucoma (POAG) is an increased intraocular pressure (IOP) caused by a resistance to aqueous humor outflow in the trabecular meshwork (TM). The molecular pathogenesis of this increase in outflow resistance in POAG has not yet been identified, but it may involve transforming growth factor TGF-ß2, which is found in higher amounts in the aqueous humor of patients with POAG. Connective tissue growth factor (CTGF) is a TGF- $\beta 2$ target gene with high constitutive TM expression. In this study, we show that either adenoviral-mediated or transgenic CTGF overexpression in the mouse eye increases IOP and leads to optic nerve damage. CTGF induces TM fibronectin and $\alpha$-SMA in animals, whereas actin stress fibers and contractility are both induced in cultured TM cells. Depletion of CTGF by RNA interference leads to a marked attenuation of the actin cytoskeleton. Rho kinase inhibitors cause a reversible decline in the IOP of CTGF-overexpressing mice to levels seen in control littermates. Overall, the effects of CTGF on IOP appear to be caused by a modification of the TM actin cytoskeleton. CTGF-overexpressing mice provide a model that mimics the essential functional and structural aspects of POAG and offer a molecular mechanism to explain the increase of its most critical risk factor. (Am J Patbol 2012, 180:23862403; http://dx.doi.org/10.1016/j.ajpath.2012.02.030)
Glaucoma, a degenerative neuropathy of the optic nerve, is the second leading cause of blindness worldwide. ${ }^{1}$ During its pathogenesis, optic nerve axons become continuously damaged at the optic nerve head, a process that leads to axonal degeneration, apoptosis of retinal ganglion cells, and finally characteristic defects in the visual field of affected patients. ${ }^{2,3}$ Several prospective, randomized, multicenter studies have identified intraocular pressure (IOP) as the most critical risk factor for onset and progression of glaucomatous optic nerve damage. ${ }^{4-9}$ The molecular mechanisms that cause axonal injury in glaucoma have not been identified conclusively but may involve blockade of both anterograde and retrograde axonal transport, ${ }^{3}$ a scenario in which IOP is likely involved. ${ }^{10}$ Similar to other neurons, retinal ganglion cells depend on neurotrophic support, which is provided by their brain target neurons and retinal interactions. Interruption of neurotrophic support may induce early loss of optic nerve axons by wallerian degeneration followed by death of retinal ganglion cell perikarya. ${ }^{11,12}$

IOP is generated and maintained by the aqueous humor circulation system in the anterior eye. ${ }^{13}$ Aqueous humor is actively secreted by the epithelial layers of the ciliary body into the posterior chamber of the eye and exits the eye in the iridocorneal angle through the trabecular meshwork (TM) and Schlemm's canal. ${ }^{14}$ In addition, there is an alternative uveoscleral pathway along the superciliary and suprachoroidal spaces of the eye. ${ }^{15}$ The TM

Supported by a grant from the Deutsche Forschungsgemeinschaft (FOR 1075, TP3).

Accepted for publication February 7, 2012

B.J. and S.K. contributed equally to this study.

CME Disclosure: None of the authors disclosed any relevant financial relationships.

Supplemental material for this article can be found at http://ajp. amjpathol.org or at http://dx.doi.org/10.1016/j.ajpath.2012.02.030.

Current address of A.A.S.: Department of Zoology, Sohag University, Sohag, Egypt.

Address reprint requests to Rudolf Fuchshofer, Ph.D., Institute of Human Anatomy and Embryology, University of Regensburg, Universitätsstr. 31, D-93053 Regensburg, Germany. E-mail: rudolf.fuchshofer@ vkl.uni-regensburg.de. 
outflow pathways provide resistance to aqueous humor outflow, and IOP builds up in response to this resistance. ${ }^{16}$ In angle-closure glaucoma, IOP is elevated because of a structurally narrow iridocorneal angle that impedes aqueous humor outflow. ${ }^{3}$ In primary open-angle glaucoma (POAG), the iridocorneal angle is structurally wide open, ${ }^{3}$ but the TM outflow pathways provide an abnormally high resistance to aqueous humor outflow. ${ }^{16}$ The molecular factors that cause an increase in outflow resistance in $P O A G$ are unclear. A characteristic structural finding in the TM of patients with POAG is the increase in extracellular fibrillar material, which has been termed "sheath-derived plaque material" and is associated with elastic fibers. ${ }^{17}$ The molecular nature of plaque material has not been identified conclusively, but fibronectin and collagen type $\mathrm{VI}$ appear to be associated with it. ${ }^{18-20}$ The amount of plaque material correlates with axonal loss in the optic nerve. ${ }^{21}$ Still, in early POAG, IOP and outflow resistance may be high even though there is no increase in extracellular fibrillar material in the TM, indicating that other molecular changes are causatively involved in generating highoutflow resistance. ${ }^{21}$

The cells of the TM have a distinct actomyosin cytoskeleton and show contractile properties. ${ }^{22,23}$ An increase in TM cellular tone increases outflow resistance in the $\mathrm{TM}^{24}$ whereas agents that lead to an impairment of the trabecular actomyosin system cause a substantial decrease in aqueous humor outflow resistance. ${ }^{22,25}$ As of today, it is not clear whether an increase in TM contractility causes or contributes to increased outflow resistance in POAG.

A large percentage of patients with POAG show increased amounts of activated transforming growth factor (TGF)- $\beta_{2}$ in the aqueous humor, ${ }^{26-33}$ and it has been hypothesized that TGF- $\beta 2$ is causatively involved in the pathogenesis of the TM outflow pathways. ${ }^{34,35}$ Accordingly, treatment of trabecular cell or organ cultures with TGF- $\beta 2$ increases the synthesis of various fibrillar extracellular matrix components, including that of fibronectin and collagen type $\mathrm{VI} .{ }^{36}$ Moreover, treatment of TM cells with TGF- $\beta 1$ increases contractility, the formation of actin stress fibers, and the expression of $\alpha$-smooth muscle actin $(\alpha-S M A){ }^{37,38}$ In recent work, we showed that the effects of TGF- $\beta 2$ on TM extracellular matrix synthesis are largely mediated through connective tissue growth factor (CTGF or CCN2), ${ }^{39}$ a member of the CCN family of matricellular regulatory proteins. ${ }^{40,41}$ Because CTGF is expressed in high amounts in the TM of the human eye, ${ }^{42}$ we hypothesized that CTGF is a critical molecule to modulate TM extracellular matrix synthesis.

In the present study, we generated and characterized mouse models that specifically overexpress CTGF in the eye. We provide evidence that the increase in CTGF causes a phenotype that shares essential elements with that observed in patients with POAG, such as open iridocorneal angle, high IOP, and degeneration of optic nerve axons. Although the increase in CTGF correlates with an increase of fibronectin within the TM, the mechanism that is responsible for the increase in IOP appears rather to involve a direct action of CTGF on the TM actomyosin cytoskeleton, a scenario that might well be similarly involved in generation of high IOP and the pathogenesis of POAG in humans.

\section{Materials and Methods}

\section{Adenoviral Gene Transfer}

Replication-deficient recombinant adenoviruses carrying an expression plasmid encoding CTGF were generated using the AdEasy $X L$ adenoviral vector system. Briefly, CTGF CDNA was cloned into the adenoviral transfer vector pShuttle-IRES-hrGFP to obtain PShuttle-IRES-hrGFP/CTGF. After recombination of linearized transfer vectors and the adenovirus backbone vector in Escherichia coli BJ5183, the recombined adenoviral constructs were transfected into XL10 Gold ultracompetent cells. Recombinant virus (Ad5GFP and Ad5-CTGF) were then transfected into HEK-293 cells (all from Stratagene, La Jolla, CA). The virus was released from the cells by a three times repeated freezing and thawing process. Lysates that contained recombinant adenoviruses were purified by ultracentrifugation. Virus pellets were resuspended in PBS, and for titration HEK-293 cells were transformed with a dilution range of $10^{-2}$ to $10^{-7}$. After 24 hours, green fluorescent protein (GFP)-positive HEK-293 cells were counted under a Zeiss Axio Imager fluorescence microscope (Carl Zeiss AG, Oberkochen, Germany). In addition, human trabecular meshwork (HTM) cells were infected with the recombinant adenovirus at titers ranging from a multiplicity of infection of 5, 10, and 25 under serum free conditions for 24 hours. After 24 hours, cells were analyzed under a Zeiss Axio Imager fluorescence microscope (Carl Zeiss AG) to assess GFP expression and fibronectin synthesis.

For transduction within the anterior chamber of mouse eyes, the titer of Ad5-CTGF and Ad5-GFP was $2.3 \times 10^{-7}$ focus-forming units per milliliter. Before intracameral injection, mice were anesthetized using a mixture of ketamine (WDT, Garbsen, Germany) and xylazine (Serumwerk, Bernburg, Germany). Ocular injections were performed using a Hamilton glass microsyringe fitted with a 35-gauge needle. Ad5-CTGF virus was injected intracamerally into one eye, whereas Ad5-GFP was injected as control into the contralateral eye. IOP measurements were made using a rebound tonometer (TonoLAB, Helsinki, Finland) as described previously. ${ }^{43}$ Briefly, measurements were conducted at the same time of day. Each reading was composed of 6 measurements averaged automatically. Highly and moderately variable readings were excluded. A mean of 5 readings was considered as a single result. For statistical analysis, Student's $t$-test was performed.

\section{Transgenic Mice}

The full-length, 1047-bp cDNA of murine CTGF was amplified by PCR and subcloned into plasmid Zero Blunt TOPO (Life Technologies, Darmstadt, Germany) by using primers EcoRI-CTGF (5'-GGTGGTGAATTCATGCTCGCCTCCGTCGCAGGTC-3') and CTGF-Spel-rev (5'-ACCACCACTAGTATGTACGGAGACATGGCGTAA-3') to obtain plasmid pCTGFRF. Correct amplification of CTGF cDNA was confirmed by using automated sequencing 
with fluorescent dideoxynucleotides (Geneart, Regensburg, Germany). The CTGF CDNA was released from pCTGFRF by digestion with EcoRI and Spel and cloned into $\mathrm{p} \beta \mathrm{B} 1$-Norrin, ${ }^{44}$ which had been digested with EcoRl and Spel. The resulting plasmid pCTGF-ipa contained the CTGF cDNA right in front of the simian virus 40 (SV40) small T-intron and the SV40 polyA-sequence. The $\beta \mathrm{B} 1$ crystallin promoter (464 bp) was obtained by digestion of $p \beta B 1-N o r r i n$ with EcoRI and cloned in front of the CTGF CDNA of plasmid pCTGF-ipa, resulting in plasmid $p \beta B 1$ CTGF. Proper orientation of the $\beta \mathrm{B} 1$-crystallin promoter was confirmed by sequencing. Constructs for microinjection were released from plasmid $\mathrm{p} \beta \mathrm{B} 1$ 1-CTGF by digestion with $\mathrm{Xbal}$ followed by gel electrophoresis.

$\mathrm{FVB} / \mathrm{N}$ transgenic mice were generated as described previously. ${ }^{45}$ Potential $\beta \mathrm{B} 1-\mathrm{CTGF}$ transgenic mice were screened by isolating genomic DNA from tail biopsies and testing for transgenic sequences by PCR. For PCR analysis, primers were used that span from the SV4O small T-intron to the SV40 polyA-sequence of the transgene. The sequences of the primers were 5'GTGAAGGAACCTTACTTCTGTGGTG-3' and 5'-GTCCTT GGGGTCTTCTACCTTTCTC-3'. A 300-bp DNA fragment was amplified and visualized by agarose gel electrophoresis and ethidium bromide staining. The thermal cycle profile was initial denaturation at $94^{\circ} \mathrm{C}$ for 2 minutes, denaturation at $94^{\circ} \mathrm{C}$ for 30 seconds, annealing at $60^{\circ} \mathrm{C}$ for 30 seconds, extension at $72^{\circ} \mathrm{C}$ for 1 minute for 30 cycles, and final extension at $72^{\circ} \mathrm{C}$ for 2 minutes.

Transgenic mice were housed under standardized conditions of $62 \%$ air humidity and $21^{\circ} \mathrm{C}$ room temperature. Feeding was ad libitum. Animals were kept at a 12-hour light/dark cycle (6:00/-18:00). This mouse strain was generated in a $\mathrm{FVB} / \mathrm{N}$ background with hereditary retinal degeneration. ${ }^{46}$ Because the purpose of this study was to analyze $\beta$ B1-crystallin-CTGF animals with a phenotypically normal retina, animals were bred in a mixed $\mathrm{FVB} / \mathrm{N} \times \mathrm{CD} 1$ background. Before enucleation of the eyes, mice were anesthetized with $\mathrm{CO}_{2}$ and euthanized by atlanto-occipital dislocation. IOP measurements were taken in 1-, 2-, and 3-month-old animals. All animal procedures performed in this study complied with the Association for Research in Vision and Ophthalmology Statement for the Use of Animals in Ophthalmic and Vision Research and with institutional guidelines.

\section{Topical Administration of Rho-Associated Protein Kinase Inhibitor}

HA-1077 (Sigma-Aldrich, Deissenhofen, Germany) was dissolved in PBS to achieve final concentrations of $2 \mathrm{mmol} / \mathrm{L}$. Before drug administration and IOP measurements, animals were anesthetized using isoflurane. Baseline IOP was recorded in wild-type (WT) littermates $(n=10)$ and in $\beta$ B1CTGF1 mice $(n=11)$ before topical treatment with HA-1077. Thereafter, $5 \mu \mathrm{L}$ of $2 \mathrm{mmol} / \mathrm{L} \mathrm{HA}-1077$ was administered to the left eye of both groups, whereas the contralateral eye was treated with PBS. IOP of treated animals was measured 1, 3, 6, 8 , and 24 hours after administration.

\section{Cell Culture}

Cultures of HTM cells were established from the eyes of four human donors according to protocols published previously. ${ }^{38,47}$ The age of the donors ranged from 34 to 76 years. HTM cells of the third to fifth passage were seeded in $35-\mathrm{mm}$ culture wells $\left(4.0 \times 10^{5}\right.$ cells per well $)$ and grown to a confluent monolayer in F10-HAM medium plus $10 \%(\mathrm{v} / \mathrm{v})$ fetal bovine serum without antibiotics in 5\% $\mathrm{CO}_{2}$ at $37^{\circ} \mathrm{C}$ (all from PAA, Pasching, Austria). After 7 days of confluence, wells were incubated in serum free medium F-10 for 24 hours followed by incubation in fresh serum free medium. Human recombinant CTGF was then added at concentrations of $50 \mathrm{ng} / \mathrm{mL}$ for different periods. CTGF was isolated and purified as described previously. ${ }^{39}$ TGF- $\beta 2$ (Roche, Mannheim, Germany) was used at a concentration of $5 \mathrm{ng} / \mathrm{mL}$. Corresponding control cells were treated equally but did not receive CTGF or TGF- $\beta 2$. Each of the described experiments was performed with each of the 4 primary cell lines. In addition, an immortalized SV40-transformed HTM cell line (HTM-N) was used to establish a cell line with stable knockdown of CTGF. The cell line had been provided by lok-Hou Pang and Louis DeSantis (Alcon Research Laboratories, Fort Worth, TX), and was cultured according to protocols published previously. ${ }^{48,49}$ Methods for securing human tissues were humane, included proper consent and approval, and complied with the Declaration of Helsinki.

\section{RNA Analysis}

HTM cells were harvested from 35-mm Petri dishes, and total RNA was extracted with TRIzol (Invitrogen, Karlsruhe, Germany) according to the manufacturer's recommendations. Structural integrity of RNA samples was confirmed by electrophoresis using $1 \%(\mathrm{w} / \mathrm{V})$ agarose gels. First-strand cDNA was prepared from total RNA using the iScript cDNA Synthesis Kit (BioRad, München, Germany) according to the manufacturer's instructions. Real-time RT-PCR was performed on a BioRad iQ5 Real-Time PCR Detection System (BioRad) with the temperature profile as follows: 40 cycles of 10 seconds melting at $95^{\circ} \mathrm{C}$ and 40 seconds of annealing and extension at $60^{\circ} \mathrm{C}$. All primer pairs (Table 1) were purchased from Invitrogen and extended over exon-intron boundaries. RNA that was not reverse transcribed served as negative control for real-time RT-PCR. To allow for relative quantification, we identified housekeeping genes by using Genex software version 5.3.2 (MultiD Analysis, Göteburg, Sweden). ${ }^{50}$ In initial experiments, real-time RT-PCR for the potential housekeeping genes GNB2L1, GAPDH, RPL32, $\beta$-tubulin, RPS9, lamin $A / C$, and B2M were performed for each of the treatment protocols. $C_{T}$ values were loaded to the software, which distinguishes genes that are regulated in a specific condition from those that are likely not. Best results were obtained for GAPDH and GNB2L1, which were both used for relative quantification of the real-time RT-PCR experiments. Quantification was performed using Bio-Rad iQ5 Standard Edition software version 2.0.148.60623 (BioRad). For Northern blot analysis of CTGF expression in the eyes of transgenic mice, 
Table 1. Sequences of Primer Pairs for Real-Time RT-PCR

\begin{tabular}{|c|c|c|c|}
\hline Type & Sequence & Position & Temperature, ${ }^{\circ} \mathrm{C}$ \\
\hline Human $\alpha$-actinin 1 (ACTN1) & $\begin{array}{l}\text { 5'-TGGCAGAGAAGTACCTGGACA-3' } \\
5^{\prime} \text {-GGCAGTTCCAACGATGTCTT-3' }\end{array}$ & $815-876$ & $\begin{array}{l}60 \\
60\end{array}$ \\
\hline Human $\alpha$-actinin 4 (ACTN4) & $\begin{array}{l}5^{\prime}-\text { TTCAACCACTTCGACAAGGA-3' } \\
5^{\prime}-\text { ATGAGGCAGGCCTTGAACT }-3^{\prime}\end{array}$ & $2379-2443$ & $\begin{array}{l}59 \\
59\end{array}$ \\
\hline Human $\alpha$-smooth muscle actin (ACTA) & $\begin{array}{l}\text { 5'-CTGAAGTACCCGATAGAACATGG-3' } \\
5^{\prime}-\text { TTGTAGAAAGAGTGGTGCCAGAT-3' }\end{array}$ & $252-328$ & $\begin{array}{l}59 \\
60\end{array}$ \\
\hline Human B2 mol/L & $\begin{array}{l}5^{\prime}-\text { TTCTGGCCTGGAGGCTATC-3' } \\
5^{\prime}-\text { TCAGGAAATTTGACTTTCCATTC-3' }\end{array}$ & $105-190$ & $\begin{array}{l}60 \\
59\end{array}$ \\
\hline Human CTGF & $\begin{array}{l}5^{\prime}-\text {-CTCCTGCAGGCTAGAGAAGC-3' } \\
5^{\prime}-\text {-GATGCACTTTTTGCCCTTCTT-3' }\end{array}$ & $884-977$ & $\begin{array}{l}59 \\
60\end{array}$ \\
\hline Human ERK1 & $\begin{array}{l}5^{\prime}-\text { CCCTAGCCCAGACAGACATC-3' } \\
5^{\prime}-\text { GCACAGTGTCCATTTTCTAACAGT-3' }\end{array}$ & $1103-1196$ & $\begin{array}{l}59 \\
59\end{array}$ \\
\hline Human ERK2 & $\begin{array}{l}\text { 5'-CAAAGAACTAATTTTTGAAGAGACTGC-3' } \\
5^{\prime}-\text { TCCTCTGAGCCCTTGTCCT-3' }\end{array}$ & $1269-1349$ & $\begin{array}{l}60 \\
59\end{array}$ \\
\hline Human FAK & $\begin{array}{l}5^{\prime}-\text { TGAGGGAGAAGTATGAGCTTGC-3' } \\
5^{\prime}-\text { TTGGCAAATAACGAATTCTCAA-3' }\end{array}$ & $550-621$ & $\begin{array}{l}60 \\
59\end{array}$ \\
\hline Human GAPDH & $\begin{array}{l}5^{\prime}-\text { AGCCACATCGCTCAGACA }-3^{\prime} \\
5^{\prime}-\text { GCCCAATACGACCAAATCC }-3^{\prime}\end{array}$ & $83-148$ & $\begin{array}{l}60 \\
60\end{array}$ \\
\hline Human GNB2L & $\begin{array}{l}\text { 5'-GCTACTACCCCGCAGTTCC-3' } \\
5^{\prime} \text {-CAGTTTCCACATGATGATGGTC-3' }\end{array}$ & $170-241$ & $\begin{array}{l}59 \\
60\end{array}$ \\
\hline Human lamin A/C (LMNA) & $\begin{array}{l}5^{\prime}-\text { GACGAGGATGAGGATGGAGA-3' } \\
5^{\prime}-\text { AGCGCAGGTTGTACTCAGC- } 3^{\prime}\end{array}$ & $1869-1959$ & $\begin{array}{l}60 \\
59\end{array}$ \\
\hline Human MLC & $\begin{array}{l}5^{\prime}-\text { GGACCTGCACGACATGCT-3' } \\
5^{\prime}-\text { ACCCATGGTGGTGAGCAG-3' }\end{array}$ & $250-325$ & $\begin{array}{l}60 \\
60\end{array}$ \\
\hline Human profilin 1 (PFN1) & $\begin{array}{l}5^{\prime}-\text {-CCTCAATGTCACTGTCACCA-3' } \\
5^{\prime}-\text { ACCACCGTGGACACCTTCT-3' }\end{array}$ & $429-502$ & $\begin{array}{l}60 \\
59\end{array}$ \\
\hline Human $R H O A$ & $\begin{array}{l}5^{\prime}-\text { GGAGCTAGCCAAGATGAAGC }-3^{\prime} \\
5^{\prime}-\text { GCCAATCCTGTTTGCCATA-3' }\end{array}$ & $663-732$ & $\begin{array}{l}59 \\
59\end{array}$ \\
\hline Human RPL32 & $\begin{array}{l}5^{\prime}-\text { GAAGTTCCTGGTCCACAACG-3' } \\
5^{\prime}-\text { GCGATCTCGGCACAGTAAG-3' }\end{array}$ & 319-395 & $\begin{array}{l}60 \\
60\end{array}$ \\
\hline Human RPS9 & $\begin{array}{l}5^{\prime}-\text { CTGCTGACGCTTGATGAGAA-3' } \\
5^{\prime}-\text { CAGCTTCATCTTGCCCTCA-3' }\end{array}$ & 234-338 & $\begin{array}{l}60 \\
60\end{array}$ \\
\hline Human $\beta$-tubulin (TUBB) & $\begin{array}{l}5^{\prime}-\text { TTAACCATGAGGGAAATCGTG-3' } \\
5^{\prime}-\text { CTGATCACCTCCCAGAACTTG-3' }\end{array}$ & $122-201$ & $\begin{array}{l}59 \\
59\end{array}$ \\
\hline Mouse GNB2L & $\begin{array}{l}5^{\prime}-\text { TCTGCAAGTACACGGTCCAG-3' } \\
5^{\prime} \text {-GAGACGATGATAGGGTTGCTG-3' }\end{array}$ & $514-604$ & $\begin{array}{l}59 \\
60\end{array}$ \\
\hline Mouse CTGF & $\begin{array}{l}5^{\prime}-\text { TGACCTGGAGGAAAACATTAAGA-3' } \\
5^{\prime} \text {-AGCCCTGTATGTCTTCACACTG-3' }\end{array}$ & $1013-1124$ & $\begin{array}{l}59 \\
59\end{array}$ \\
\hline
\end{tabular}

lenses and the rest of the eyes were homogenized in TRIzol and RNA was extracted as described. Two milligrams of RNA was fractionated by gel electrophoresis in $1 \%$ (w/v) agarose gels with $2.2 \mathrm{~mol} / \mathrm{L}$ formaldehyde, transferred onto a nylon membrane (Roche, Basel, Switzerland) by vacuum blotting, and cross-linked at $1600 \mathrm{~mJ}$ (Herolab CL-1; Wiesloch, Germany). Membranes were prehybridized in Dig Easy Hyb (Roche) for 1 hour at $68^{\circ} \mathrm{C}$. Hybridization was performed at $68^{\circ} \mathrm{C}$ overnight in Dig Easy Hyb containing $50 \mathrm{ng} / \mathrm{mL}$ of a specific antisense probe. Riboprobe synthesis was performed as described previously. ${ }^{47}$ For synthesis of CTGF specific probes forward primer 5'-CACAAGGGCCTCTTCTGCGA-3' and reverse primer 5'-TTTCCTCCAGGTCAGCTTCG-3' were used. After hybridization, the membranes were washed twice in $2 \times$ standard saline citrate and $0.1 \%(\mathrm{v} / \mathrm{v})$ SDS for 10 minutes at room temperature, then in $0.1 \%$ SDS for 15 minutes at $70^{\circ} \mathrm{C}$ and once for 5 minutes in washing buffer (100 mmol/L maleic acid, $150 \mathrm{mmol} / \mathrm{L} \mathrm{NaCl}, \mathrm{pH} 7.5$, and $0.3 \%$ [v/v] Tween 20). Membranes were blocked in blocking solution (100 mmol/L maleic acid, $150 \mathrm{mmol} / \mathrm{L} \mathrm{NaCl}$, $\mathrm{pH} 7.5,1 \%[\mathrm{v} / \mathrm{v}]$ blocking reagent, Roche). Alkaline phosphatase-conjugated anti-digoxygenin antibody ( $\alpha$-DIGAP; Roche) was added at a dilution of 1:10,000 in blocking solution and allowed to react for 30 minutes at room temperature. After incubation, the membranes were washed four times for 10 minutes each in washing buffer and equilibrated in detection buffer $(100 \mathrm{mmol} / \mathrm{L}$ Tris $/ \mathrm{HCl}$, $100 \mathrm{mmol} / \mathrm{L} \mathrm{NaCl}, \mathrm{pH}$ 9.5) for 10 minutes. For detection of chemiluminescence, membranes were incubated for 5 minutes with chemiluminescent substrate (CDP-Star; Roche) diluted 1:100 in detection buffer. Chemiluminescence was detected on a LAS 3000 imaging workstation (Fujifilm Europe GmbH, Düsseldorf, Germany), with exposure times ranging from 40 minutes to 1 hour. For normalization, amount and quality of ribosomal RNA were visualized by methylene blue staining of $28 \mathrm{~S}$ and $18 \mathrm{~S}$ rRNA bands. The relative amounts were determined by normalizing chemiluminescence mRNA signals with methylene blue stained rRNA bands by using appropriate software (AIDA Image analyzer software version 4.06.034; Raytest, Straubenhardt, Germany).

\section{Generation and Transfection of a CTGF pSilencer Vector}

The insert sequences (Table 2) for the human CTGF pSilencer vector were designed using web-based criteria and obtained by Invitrogen. Vectors were generated with 
Table 2. Sequences of Small Interfering RNA (siRNA) Oligonucleotides

\begin{tabular}{lcc}
\hline \multicolumn{1}{c}{ siRNA oligonucleotides } & Sequence & Position \\
\hline pSilencer sense-insert & 5'-GATCCTGTTCTCTTCCAGGTCAGCTTCAAGAGAGCTGACCTGGAAGAGAACATTA-3' & 978 \\
pSilencer antisense-insert & 5'-AGCTTAATGTTCTCTCCAGGTCAGCTCTCTTGAAGCTGACCTGGAAGAGAACAG-3' \\
\hline
\end{tabular}

a pSilencer 4.1-CMV hygro construction kit (Ambion, Austin, TX) according to the manufacturer's instructions. HTM-N cells were transfected at $75 \%$ of confluence in a six-well plate with $2 \mu \mathrm{g}$ of the vector and with $2 \mu \mathrm{L}$ of Lipofectamine 2000 transfection reagent, according to the manufacturer's instructions (Invitrogen). For selection of cells containing the vector, cells were incubated in Dulbecco's modified Eagle's medium (DMEM) containing $250 \mu \mathrm{g} / \mathrm{mL}$ of hygromycin. To analyze the expression of CTGF, cells were seeded in 6 well plates. After 2 days of confluence, cells were incubated for 24 hours in serum free medium before they were harvested for RNA and protein isolation.

\section{Light and Electron Microscopy}

Eyes were obtained from animals at 1,2, and 3 months of age. Eyes were enucleated and fixed in Karnovsky's solution (2.5\% glutaraldehyde and $2.5 \%$ paraformaldehyde in $0.1 \mathrm{M}$ cacodylate buffer) for 24 hours. ${ }^{51}$ After rinsing in $0.1 \mathrm{M}$ cacodylate buffer, postfixation was accomplished in a mixture of $1 \% \mathrm{OsO}_{4}$ and $0.8 \%$ potassium ferrocyanide in $0.1 \mathrm{M}$ cacodylate buffer for 2 hours at $48^{\circ} \mathrm{C}$. Eyes were then dehydrated in a graded series of ethanol and embedded in Epon (Serva, Heidelberg, Germany). Semithin sections $(1 \mu \mathrm{m})$ were collected on uncoated glass slides and stained with methylene blue/azure II. ${ }^{52}$ Ultrathin sections were mounted on uncoated copper grids, stained with uranyl acetate and lead citrate, and examined on a Zeiss Libra transmission electron microscope (Carl Zeiss AG). Myelinated optic nerve axons were visualized by paraphenylenediamine (Roth, Karlsruhe, Germany) staining of Epon-embedded semithin sections. ${ }^{53}$ In brief, $1 \%$ paraphenylenediamine in $98 \%$ ethanol was freshly prepared and stored at daylight for 3 days before use until the solution had darkened. The solution is stable for 1 week in the dark at $48^{\circ} \mathrm{C}$. Optic nerve cross sections were stained for 2 to 3 minutes at room temperature, and staining was differentiated with changes of $100 \%$ ethanol. To count the total number of optic nerve axons in 1-, 2-, and 3-month-old animals, stained-stained cross-sections were visualized by bright field microscopy using a 100x oil immersion objective for highest resolution. Myelinated axons were identified and counted (Axiovision software version 3.0, Carl Zeiss AG).

\section{Immunohistochemistry}

Eyes were enucleated, fixed in 4\% (w/v) paraformaldehyde in PBS for 1 hour. After fixation, the lens was removed and the eye was equilibrated in $10 \%, 20 \%$, and $30 \%$ sucrose for 4 hours, embedded in Tissue-Tek optimal cooling temperature compound (Sakura Finetek
Europe B.V., Zoeterwoude, the Netherlands), and stored at $-20^{\circ} \mathrm{C}$. Frozen sections were cut on a cryostat. After blocking with $3 \%$ bovine serum albumin in PBS for 1 hour at room temperature, frozen sections were incubated with anti-fibronectin rabbit IgG (1:500; Dako, Glostrup, Denmark) or anti- $\alpha$-SMA mouse IgG (1:100; Serotec, Kidlington, England) at $4^{\circ} \mathrm{C}$ overnight. Afterward, tissue sections were washed three times with PBS followed by incubation for 1 hour at room temperature with Alexa Fluor 488conjugated anti-rabbit IgG (Invitrogen) or Alexa 546conjugated anti-mouse IgG (Invitrogen), respectively. As a control for unspecific binding of secondary antibodies, negative controls were performed, which were handled similarly but incubated in PBS without primary antibodies. After washing three times with PBS, the slides were mounted using the DakoCytomation fluorescent mounting medium with DAPI 1:10 (Dako). Slides were dried overnight at $4^{\circ} \mathrm{C}$ before microscopy.

\section{Immunocytochemistry}

HTM, HTM-5, and pSiCTGF cells were plated on 12-well plates with coverslips at a density of $5 \times 10^{4}$ cells per well and were allowed to attach for 24 hours before treatment. Cells were starved under serum free condition for 24 hours and then treated with recombinant CTGF or transfected with adenoviral vectors as described. Cells were fixed with $4 \%$ (w/v) paraformaldehyde for 5 minutes. After blocking with $5 \%$ BSA in PBS for 1 hour at room temperature, cells were incubated with antivinculin mouse IgG (1:200; Sigma-Aldrich) or antifibronectin rabbit IgG (1:500; Dako) at $4^{\circ} \mathrm{C}$ overnight. Afterward, coverslips were washed three times with PBS, followed by incubation for 1 hour at room temperature with Alexa Fluor 488-conjugated anti-mouse IgG (Invitrogen) or Alexa 546-conjugated anti-rabbit IgG (Invitrogen), respectively. For staining of actin stress fibers, phalloidin-TRITC (Sigma-Aldrich) diluted 1:1000 in PBS was added for 1 hour at room temperature. As a control for unspecific binding of secondary antibodies, negative controls were performed as described. After washing the slides three times with PBS, coverslips were mounted using the DakoCytomation fluorescent mounting medium with DAPI 1:10 (Dako). Slides were dried overnight at $4^{\circ} \mathrm{C}$ before microscopy. Immunofluorescence was visualized using a Zeiss Axio Imager fluorescence microscope (Carl Zeiss AG). The length of phalloidin-TRITC stained actin stress fibers was measured on five coverslips per treatment by visualizing and digitizing 100 randomly selected fields with a $40 \times$ lens. The length of the individual stress fibers in each cell was measured using Zeiss Axio Vision Release software version 4.8 (Carl Zeiss). 


\section{Western Blot Analysis}

To obtain protein extracts of cells grown on tissue culture dishes, cells were directly lysed in RIPA Iysis buffer (150 $\mathrm{mmol} / \mathrm{L} \mathrm{NaCl}, 1 \% \mathrm{NP}-40,0.5 \%$ deoxycholic acid, $0.1 \%$ SDS, and $50 \mathrm{mmol} / \mathrm{L}$ Tris, $\mathrm{pH} 8$ ), and protein content was measured with the bicinchoninic acid protein assay (Pierce, Rockford, IL). Alternatively, cell culture medium was collected and used directly for Western blotting. Proteins were separated by SDS-PAGE and transferred to polyvinylidene difluoride membranes. Western blot analysis was performed with specific antibodies as described previously. ${ }^{47}$ Antibodies were used as follows: mouse anti- $\alpha$-SMA (1:500; Serotec), goat anti- $\alpha$-actinin, goat anti-CTGF, rabbit anti-(p-Tyr-397) focal adhesion kinase (all 1:500; Santa Cruz Biotechnology, Santa Cruz, $\mathrm{CA})$, rabbit anti-(p-)extracellular signal-regulated kinase 1/2, rabbit anti-integrin $\beta_{1}$ (both 1:1000; Cell Signaling Technologies, Beverly, MA), rabbit anti-fibronectin 1:1000 (Dako); mouse anti-vinculin (1:1000; Sigma-Aldrich), chicken anti-goat, chicken anti-mouse, and chicken anti-rabbit IgG, coupled to horseradish peroxidase (all 1:2000; Santa Cruz). Chemiluminescence was detected on an LAS 3000 imaging workstation. For normalization of the signals seen in Western blots, blotted membranes were stained with Coomassie blue and digitized. Three major bands on each lane were selected, which appeared not to be regulated by qualitative assessment. The intensity of each of these bands was determined using appropriate software (AIDA Image analyzer software version 4.06.034; Raytest), and the mean intensity per lane was calculated. This mean was used to normalize the signal intensity of the bands detected by Western blot analysis.

\section{RhoA Activity Assay}

To determine the effect of CTGF on the activity of the small GTPase RhoA, we used a RhoA activity assay kit (Millipore, Billerica, MA). HTM cells were seeded in 75$\mathrm{cm}^{2}$ cell culture flasks. After confluence, the cells were serum starved for 24 hours and treated with $50 \mathrm{ng} / \mathrm{mL}$ of CTGF for 3 hours. Isolation of proteins and determination of activated RhoA was performed according to the manufacturer's instructions. To evaluate the whole amount of RhoA in a parallel approach, $20 \mu \mathrm{L}$ of total cell lysate were loaded onto a SDS-PAGE, and Western blot was performed as described for RhoA activity assay.

\section{Collagen Contraction}

HTM cells were collected by treatment of cultures with trypsin-EDTA for 5 minutes and resuspended in DMEM at a density of $2 \times 10^{6}$ cells $/ \mathrm{mL}$. A total of $350 \mu \mathrm{L}$ of collagen type I (3.75 mg/mL; BD Bioscience, San Jose, CA), $1.4 \mathrm{~mL}$ of $1.5 \times$ DMEM, $100 \mu \mathrm{L}$ of DMEM, and $250 \mu \mathrm{L}$ of the cell suspension were mixed in each well of a six-well plate (final concentration of type I collagen, $0.66 \mathrm{mg} / \mathrm{mL}$; final cell density, $5 \times 10^{5}$ cells $/ \mathrm{mL}$ ). Formation of a collagen gel was induced by incubation at $37^{\circ} \mathrm{C}$ under $5 \%$ $\mathrm{CO}_{2}$ for 1 hour. A total of $1 \mathrm{~mL}$ of DMEM, with or without
CTGF or TGF- $\beta 2$, was added on top of the collagen gels, and the gels were carefully freed from the bottom of the culture wells with a spatula (final concentration of CTGF, $50 \mathrm{ng} / \mathrm{mL}$; final concentration of TGF- $\beta 2,5 \mathrm{ng} / \mathrm{mL}$ ). The area of the collagen gels was measured after 24 hours with the help of an LAS 3000 imaging workstation and the appropriate software (AIDA Image analyzer software version 4.06.034). For normalization, the mean area of the collagen gel with untreated HTM cells was set at 1 .

\section{Number of Experiments and Statistical Analysis}

To assess the effects of a 24-hour treatment with CTGF, each Northern and Western blot experiment was repeated at least three times with RNA or protein extract from primary HTM cell lines of four different donors, respectively. Each real-time RT-PCR analysis was performed in duplicate and repeated at least three times with RNA from HTM cell lines of four different donors. Student's t-test was used for statistical analysis of the RNA data.

\section{Results}

\section{Adenovirus-Mediated CTGF Overexpression and TM Biology}

To investigate the effects of CTGF on TM biology in the living eye, we generated an adenoviral construct (Ad5CTGF) with the coding sequences of murine CTGF under control of the CMV promoter (see Supplemental Figure S1A at http://ajp.amjpathol.org). IRES-GFP sequences were included to facilitate detection of virus-transduced cells. In pilot experiments, we analyzed the bioactivity of Ad5-CTGF by transducing cells from the HTM-N cell line (multiplicity of infection of 5, 10, and 25). By fluorescence microscopy, multiple cells were observed that expressed GFP in both Ad5-CTGF-transduced cells and control cells transduced with a control vector (Ad5-GFP) containing only IRES-GFP sequences (see Supplemental Figure S1A at http://ajp.amjpathol.org). In contrast to Ad5-GFPtransduced control cells, HTM-N cells transduced with Ad5-CTGF showed intense staining for fibronectin (see Supplemental Figure S1B at http://ajp.amjpathol.org), a characteristic CTGF-regulated gene in TM cells. ${ }^{39}$ In addition, by real-time RT-PCR the mean \pm SD expression of fibronectin mRNA was found to be significantly higher (2.67-fold \pm 0.41 -fold) than in control cells.

We next used our viral vectors to treat the eyes of mice. Ad5-CTGF was injected into the anterior chamber of one eye (2.3 $\times 10^{-7}$ plaque-forming units per milliliter), whereas control virus (Ad5-GFP) was injected at the same concentration into the contralateral eye. Two weeks after injection, no major structural changes were observed in the chamber angle of both eyes when investigated by light microscopy of semithin sections (Figure $1 \mathrm{~A}$ ). No signs of ocular inflammation were observed, and the chamber angle, including TM and Schlemm's canal, was wide open. In both control and experimental eyes, GFP labeling was observed in the peripheral corneal 
A

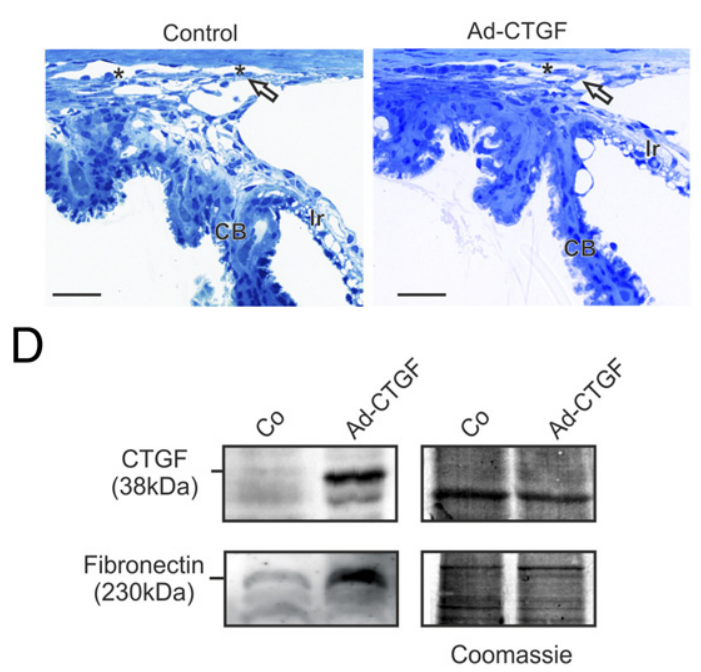

F

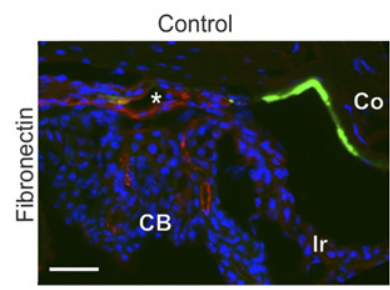

Ad-CTGF

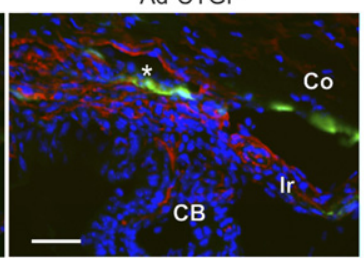

B

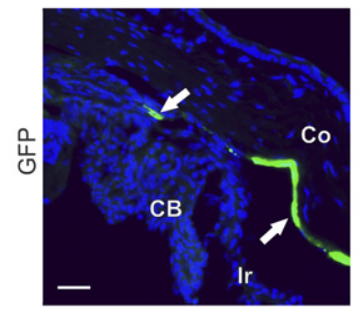

E

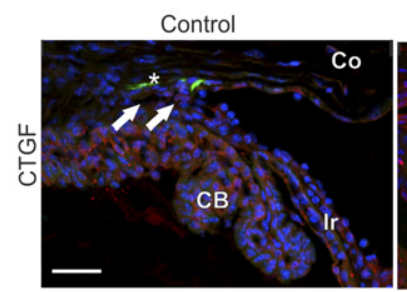

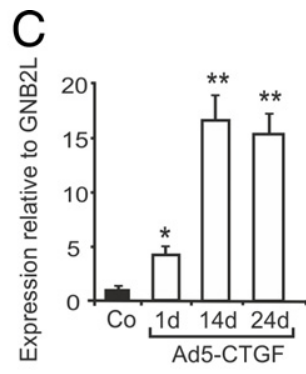

Ad-CTGF

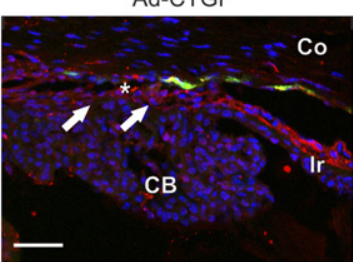

$\mathrm{G}$

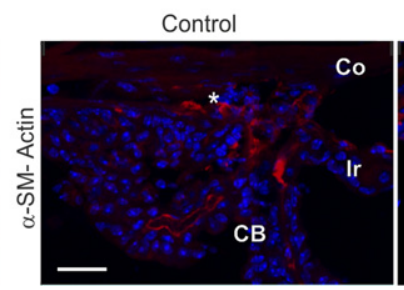

Figure 1. Adenoviral-mediated overexpression of CTGF in the chamber angle of the mouse eye. A: Light microscopy: eyes treated with control virus (Ad5-GFP) or Ad5-CTGF show no structural abnormalities in the ciliary body (CB), iris (Ir), TM (arrows), and Schlemm's canal (SC, asterisk). B: GFP labeling in TM and corneal endothelium (arrows) after Ad5-GFP injection. C: Real-time RT-PCR for CTGF mRNA in limbal tissues of Ad5-GFP- (Co) and Ad5-CTGF-treated eyes 1 to 24 days after treatment. Mean value of Ad5-GFP-treated eyes was set at $1\left({ }^{*} P<0.05,{ }^{* *} P<0.01\right.$; reference gene: GNB2L). D: Western blot analysis for fibronectin of CTGF in limbal tissues of eyes 2 months after injection of Ad5-GFP or Ad5-CTGF. Coomassie blue staining to confirm equal loading of proteins. E: Immunohistochemistry (IHC) for CTGF (red) in the anterior eye of animals 2 months after Ad5-GFP or Ad5-CTGF treatment. GFP labeling is seen in virus-transduced cells (green). In both experimental and control eyes, immunostaining for CTGF is seen in the corneal endothelium and in the stroma of the ciliary processes. In control eyes, no staining for CTGF is seen in the TM (arrows), whereas the TM of experimental eyes shows distinct immunoreactivity for CTGF (arrows) F: IHC for fibronectin (red) in the chamber angle of eyes 2 months after Ad5-GFP or Ad5-CTGF treatment. GFP labeling in virus-transduced cells (green). In control eyes, fibronectin is seen adjacent to the SC and in the stroma of the ciliary processes. After Ad5-CTGF injection, immunoreactivity for fibronectin around SC is more intense and detectable in the Ir root throughout the CB and the sclera close to the outer wall of SC. G: IHC for $\alpha$-SMA (red) in eyes 2 months after treatment with Ad5-GFP or Ad5-CTGF. In Ad5-GFP-injected eyes, $\alpha$-SMA is detectable in several cells in the TM and around ciliary process vessels. In contrast, in the experimental eye $\alpha$-SMA staining is seen in cells throughout the entire TM and in the stroma of the CB and Ir. Scale bar $=50 \mu \mathrm{m}$.

endothelium and the TM (Figure 1B). Real-time RT-PCR analyses of RNA from the limbal region of the eyes detected a significant (4.7-fold \pm 0.1-fold) increase of mRNA for CTGF 24 hours after injection of Ad5-CTGF when compared with eyes injected with control virus (Figure 1C). The expression was considerably higher 14 and 28 days after injection (17.1-fold \pm 1 -2-fold and 15.2fold \pm 0.9-fold; Figure 1C) and resulted in a massive increase in the amounts of CTGF in proteins from the limbal region when investigated by Western blotting 2 months after injection (Figure 1D). In Ad5-GFP-transduced eyes, immunoreactivity for CTGF was seen in the corneal endothelium and in the stroma of iris and ciliary body (Figure 1E). No or only faint staining was detected in the TM (Figure 1E). In contrast, in Ad5-CTGF-transduced eyes, a distinct positive staining for CTGF was seen throughout the entire TM (Figure 1E). Compared with Ad5-GFP-transduced eyes, immunostaining in the anterior stroma of the iris was much stronger, whereas no major differences were observed in the stroma of the ciliary body. In control eyes, immunoreactivity for fi- bronectin was confined to a small area adjacent to the inner and outer walls of Schlemm's canal and was observed in the stroma of the ciliary processes (Figure $1 \mathrm{~F}$ ). In contrast, 2 months after Ad5-CTGF injection, immunoreactivity for fibronectin around Schlemm's canal and in the ciliary process stroma was more intense and extended to the iris root throughout the base of the ciliary processes and the sclera close to the outer wall of Schlemm's canal (Figure 1F). Western blot experiments confirmed the results obtained with immunohistochemistry $(\mathrm{IHC})$ and showed an increase in the amounts of fibronectin in proteins from limbal tissues of Ad5-CTGF-injected eyes when compared with control eyes (Figure 1D). A parallel increase in immunoreactivity was seen for $\alpha$-SMA. Control eyes showed immunoreactivity for $\alpha$-SMA only in several cells in and close to the TM and around the capillary wall of ciliary process vessels (Figure 1G). In contrast, in experimental eyes 2 months after Ad5-CTGF injection, $\alpha$-SMA staining was seen in cells throughout the entire TM and in the stroma of ciliary body and iris (Figure $1 \mathrm{G}$ ). 
A

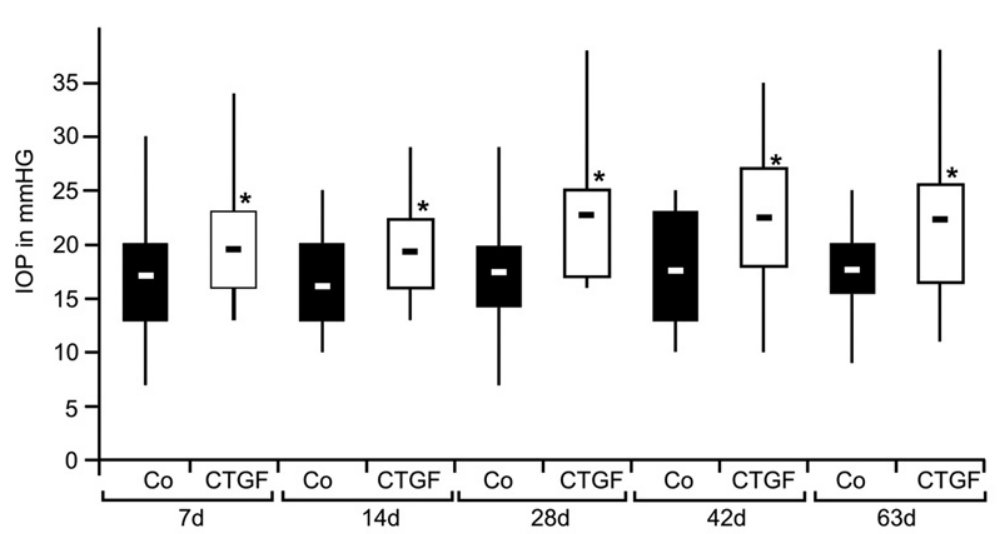

B

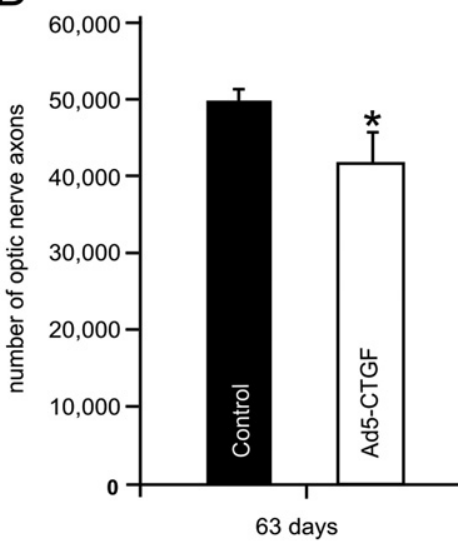

C

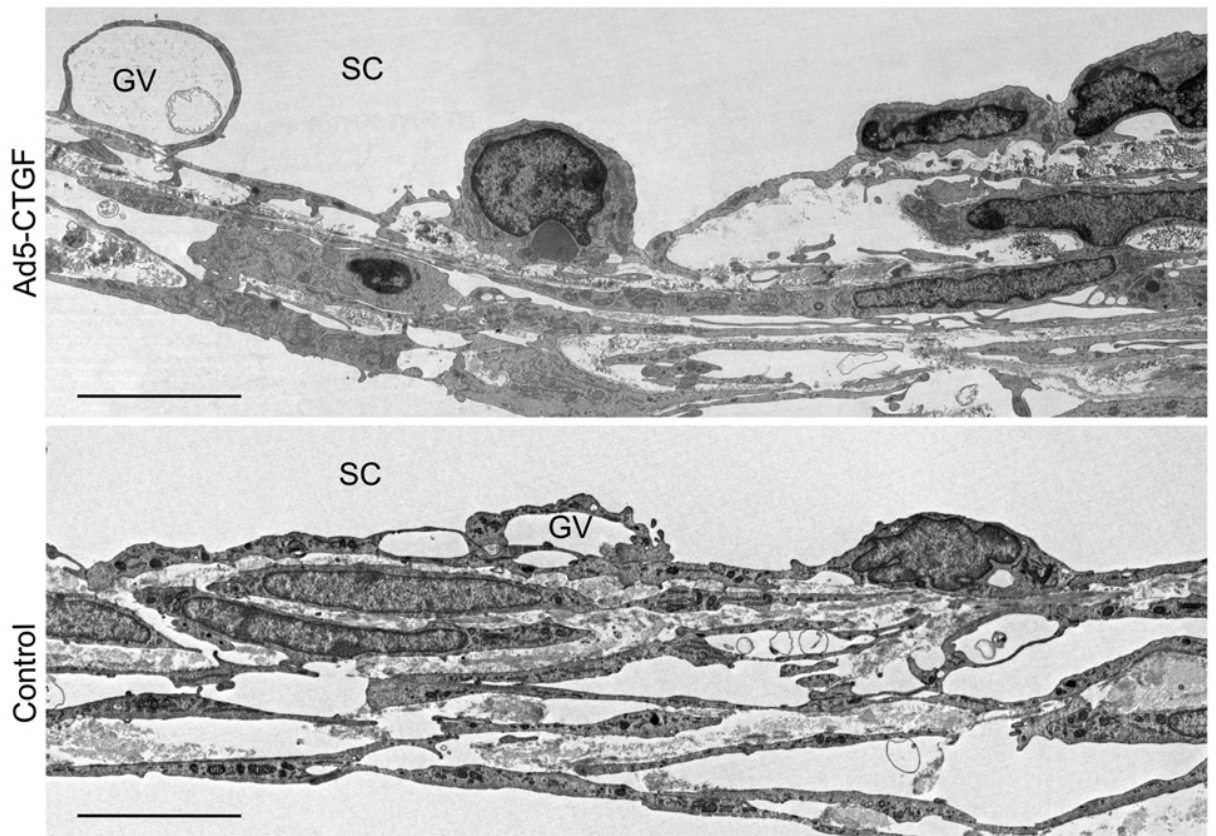

Figure 2. High IOP in Ad5-CTGF-injected eyes is associated with loss of optic nerve axons and normal ultrastructure of trabecular meshwork outflow pathways A: IOP in eyes of animals injected with Ad5-GFP or Ad5-CTGF 7 to 63 days after injection. Box and whisker blots showing median, upper and lower quartile, and smallest and greatest values in the distribution $\left({ }^{*} P<0.05\right)$. B: Number of axons in the optic nerve of eyes injected with control virus (Ad5-GFP) or Ad5-CTGF 63 days after injection. C: Electron micrographs of TM and Schlemm's canal (SC) in eyes injected with Ad5-GFP or Ad5-CTGF 62 days after injection. The ultrastructure of TM and SC endothelium is not obviously different between both eyes. Giant vacuoles (GVs) are present in SC endothelium, and numerous optically empty spaces are present underneath the inner wall endothelium in both eyes. Scale bar $=2.5 \mu \mathrm{m}$.

\section{Increasing Amounts of CTGF Cause an Increase in IOP and Optic Nerve Damage}

To learn whether increasing amounts of CTGF in the mouse chamber angle would affect aqueous humor outflow, we measured IOP noninvasively by tonometry (Figure 2A). Immediately before injection, baseline IOP was determined in eyes destined for Ad5-CTGF injection (16.7 $\pm 0.56 \mathrm{~mm} \mathrm{Hg}, n=30$ ) or in contralateral eyes destined for injection with control virus $(16.52 \pm 0.81 \mathrm{~mm}$ $\mathrm{Hg}, n=26)$. Seven days after injection, IOP was measured at $19.53 \pm 0.96 \mathrm{~mm} \mathrm{Hg}$ in Ad5-CTGF-injected eyes $(n=26)$ versus $17.09 \pm 0.75 \mathrm{~mm} \mathrm{Hg}$ in eyes injected with control virus $(n=25)$, a difference that was statistically significant $(P<0.05)$. IOP remained high in Ad5-CTGF-injected eyes 14 days after injection (19.13 \pm
$0.98 \mathrm{~mm} \mathrm{Hg}, n=24$, versus $16.12 \pm 0.82 \mathrm{~mm} \mathrm{Hg}, n=25$, $P<0.05)$. Twenty-eight days after injection, the difference between Ad5-CTGF-injected eyes $(22.53 \pm 1.25$ $\mathrm{mm} \mathrm{Hg}, n=19)$ and control eyes $(17.42 \pm 0.92 \mathrm{~mm} \mathrm{Hg}$, $n=26)$ further increased $(P<0.01)$ and remained at comparable levels 42 days after injection $(22.35 \pm 1.02$ $\mathrm{mm} \mathrm{Hg}, n=17$, versus $17.12 \pm 1.27 \mathrm{~mm} \mathrm{Hg}, n=16, P<$ $0.01)$ and 63 days after injection $(22.27 \pm 1.45 \mathrm{~mm} \mathrm{Hg}$, $n=11$ versus $17.34 \pm 0.93 \mathrm{~mm} \mathrm{Hg}, n=19, P<0.05)$ (Figure 2A). We now were interested to know whether the continuously higher IOP would lead to optic nerve damage in experimental eyes and counted the total number of cross-sectioned optic nerve axons in Ad5CTGF-injected eyes and control eyes. Sixty-three days after injection, 50,046 \pm 1040 axons $(n=5)$ were counted in eyes injected with control virus versus 
43,381 \pm 1040 axons $(n=5)$ in Ad5-CTGF-injected eyes, indicating a significant $(P<0.05)$ axonal loss in CTGF-transduced eyes (Figure 2B).

By light microscopy of eyes 63 days after injection, the chamber angle morphologic characteristics of Ad5CTGF-treated eyes were not obviously different from control virus-injected eyes or from those investigated 14 days after injection (not shown). We next performed transmission electron microscopy to find out whether the increase in IOP could be caused by an obstruction of the TM outflow pathways (eg, due to an increased deposition of fibrillar extracellular matrix components). The ultrastructure of TM and Schlemm's canal endothelium was overall not obviously different between controls and Ad5CTGF-injected eyes (Figure 2C). Moreover, numerous optically empty spaces and putative pathways for aqueous humor were present underneath the inner wall endothelium in both types of eyes (Figure 2C). In addition, in both Ad5-CTGF-injected and control virus-injected eyes, giant vacuoles were frequently seen in the inner wall endothelium of Schlemm's canal (Figure 2C), indicating flow of aqueous humor across the endothelial barrier. ${ }^{16}$ In summary, the increase in IOP in Ad5-CTGF-injected eyes appeared not to be caused by a pronounced increase in fibrillar extracellular matrix in the TM impeding trabecular aqueous humor outflow.

\section{CTGF Modifies the Actin Cytoskeleton of TM Cells}

We next turned our attention to the action of CTGF on the TM actin cytoskeleton because we had observed an increase in immunoreactivity for $\alpha$-SMA in this region. We first investigated the influence of CTGF on the contractility of HTM cells by performing collagen contraction assays. To this end, HTM cells were cultured in a three-dimensional collagen gel, and the change over time in gel surface area was analyzed as measure of cell contractility. Treatment with $50 \mathrm{ng} / \mathrm{mL}$ of recombinant human CTGF for 24 hours caused a significant reduction of gel area to $73.4 \% \pm 13 \%$ when compared with controls (Figure $3 \mathrm{~A}$ ). We next compared the results obtained with CTGF with TGF- $\beta 2$ because TGF- $\beta 1$ signaling is known to cause an increase in collagen gel contraction by bovine TM cells ${ }^{37}$ and induces the expression of $\alpha$-SMA in HTM cells. ${ }^{38}$ We used TGF- $\beta 2$ in contrast to TGF- $\beta_{1}$ because it is the major TGF- $\beta$ isoform in the aqueous humor ${ }^{36}$ and after treatment with $5 \mathrm{ng} / \mathrm{mL}$ of TGF- $\beta 2$ for 24 hours a reduction of gel area by $80 \% \pm 7 \%$ was observed (Figure $3 \mathrm{~A}$ ), a result comparable to that observed for CTGF.

We next treated HTM cells with CTGF and investigated its effects on the actin cytoskeleton by staining actin stress fibers with phalloidin. Treatment with $50 \mathrm{ng} / \mathrm{mL}$ of CTGF for 24 hours caused a marked change in HTM cell phenotype because cells became larger and more flat than in controls and contained numerous longitudinally arranged actin stress fibers (Figure 3B), which were significantly longer than those in controls (Figure 3D). Western blotting of proteins from treated cells showed a 1.4fold \pm 0.2 -fold $(P<0.03)$ increase in $\alpha$-SMA when compared with untreated controls (Figure 3C). In addition, Western blotting with antibodies specific for both actin-crosslinking proteins $\alpha$-actinin 1 and 4 showed a 2.7 -fold \pm 0.3 -fold increase after treatment with $50 \mathrm{ng} / \mathrm{mL}$ of CTGF (Figure $3 \mathrm{C}$ ). Finally, we transduced HTM cells with Ad5-CTGF to observe whether this would cause a similar change in phenotype as observed after treatment with CTGF. Again, in culture dishes treated with Ad5CTGF, cells became broader and contained more actinstress fibers (Figure 3E).

To learn about the signaling mechanisms that are involved in the action of CTGF on the TM actin cytoskeleton, we next analyzed the amounts of the small GTPase RhoA, which is known to regulate the formation of actin stress fibers. ${ }^{54,55}$ The amounts of inactive RhoA that were detected by Western blotting did not differ between control and CTGF-treated cells (Figure 4A). In contrast, the amounts of the GTP-bound active form of RhoA, which was barely detectable in control cells, were found to be strikingly increased 3 hours after treatment with $50 \mathrm{ng} / \mathrm{mL}$ of CTGF (Figure 4A). We now analyzed the amounts of myosin regulatory light chains (MLCs) known to facilitate the interaction of myosin with actin filaments for contractile activity. Treatment with CTGF for 3 hours increased the amounts of phosphorylated MLCs, an effect that was highest (2.7-fold \pm 0.9 -fold) when $5 \mathrm{ng} / \mathrm{mL}$ of CTGF was added to the culture medium. Finally, we investigated the amounts of focal adhesion kinase (FAK) and extracellular regulated kinase 1/2 (ERK1/2) and their activated phosphorylated forms (pFAK and pERK1/2). Both FAK and ERK $1 / 2$ are signaling molecules that are able to induce stress fibers after activation. CTGF treatment induced the phosphorylation of both FAK and ERK 1/2. Accordingly, a 2.8- \pm 0.6 -fold (pFAK) or 2.2-fold \pm 0.6 -fold (pERK1/2) increase was observed after treatment with $5 \mathrm{ng} / \mathrm{mL}$ of CTGF for 3 hours (Figure 4A). Because our data also indicated that the amounts of unphosphorylated MLCs (2.2-fold \pm 0.2 -fold) and ERK1 (44 kDa) and ERK2 (42 $\mathrm{kDa}$ ) (3.3-fold \pm 1.4-fold each) increased on treatment with CTGF, we analyzed by real-time RT-PCR the effects of CTGF on the transcription of RhoA, MLC, FAK, and ERK1 and 2. Although treatment with CTGF did not cause significant changes in the amounts of mRNA for RhoA, FAK, and ERK2, we observed a significant up-regulation of mRNA for MLCs (2.6-fold \pm 0.7 -fold) and ERK1 (1.9fold \pm 0.5 -fold) (Figure 4B).

\section{Depletion of CTGF Weakens the TM Actin Cytoskeleton}

TM cells have been shown to express substantial amounts of CTGF both in vitro and in vivo. ${ }^{42,47}$ Because treatment with CTGF caused a marked up-regulation of TM actin stress fibers, we wondered whether endogenous CTGF plays an important role as signaling molecule to maintain the TM actin cytoskeleton. To this end, we generated a TM cell line with a permanent depletion in CTGF. HTM-N cells were stable transfected with pSiCTGF, a vector coding for a short hairpin RNA against 
A
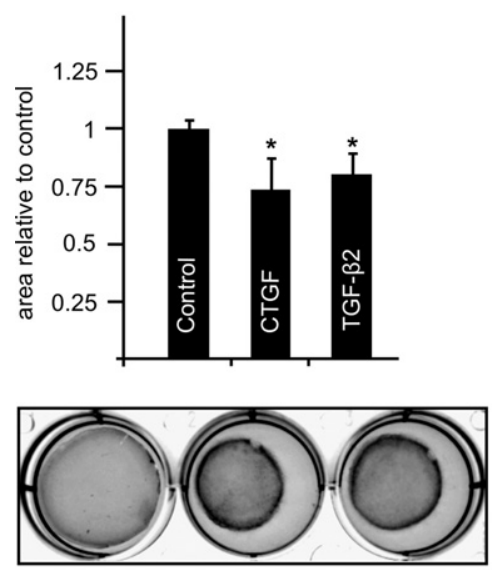

Control
B

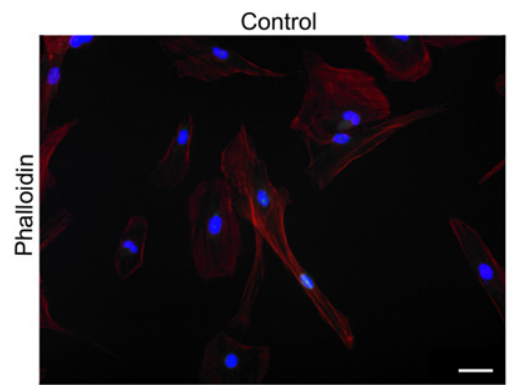

CTGF

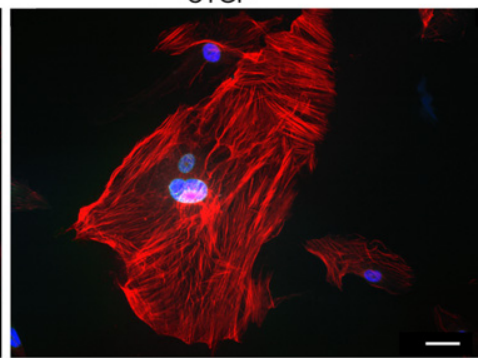

C
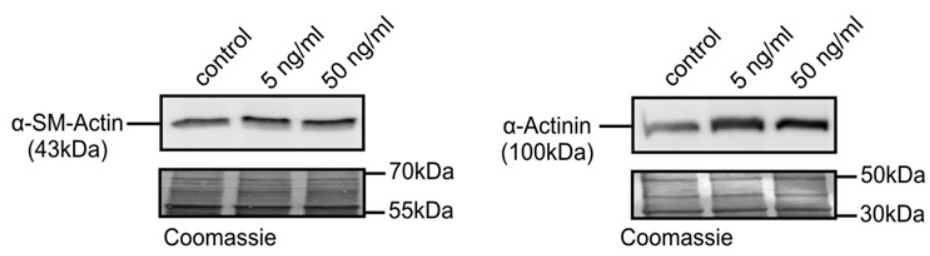

D

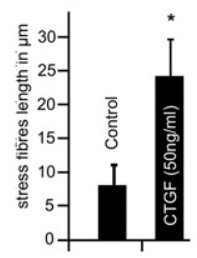

E

Control

Control (Ad-GFP)

Ad5-CTGF
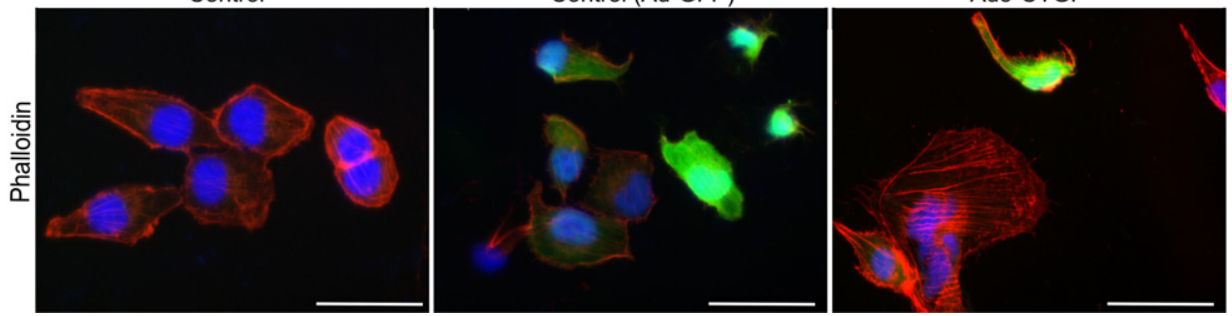

Figure 3. CTGF induces contraction and formation of actin stress fibers in HTM cells. A: Collagen contraction assay with HTM cells seeded in a matrix of collagen type I and treated with CTGF or TGF- $\beta 2$. After 24 hours, culture wells were photographed (bottom) and area of matrices measured (top). The area obtained in controls was set at $1\left(n=4:{ }^{*} P<0.05\right)$. B: Phalloidin labeling (red) of actin stress fibers in control HTM cells or 24 hours after treatment with CTGF. Nuclear DNA was stained with DAPI (blue). Scale bar $=50 \mu \mathrm{m}$. C: Western blot analysis for $\alpha$-SMA or $\alpha$-actinin in proteins of cultured HTM cells after treatment with 5 and $50 \mathrm{ng} / \mathrm{mL}$ of CTGF for 2 hours. Coomassie blue staining to confirm equal loading of proteins. D: Length of phalloidin-labeled stress fibers 24 hours after treatment with CTGF $\left(n=4 ;{ }^{*} P<0.05\right)$. E: Phalloidin labeling (red) of actin stress fibers in HTM cells or 24 hours after treatment with control virus (Ad5-GFP) or Ad5-CTGF GFP labeling (green) shows virus-infected cells; nuclear DNA is labeled with DAPI (blue). Scale bar $=50 \mu \mathrm{m}$.

CTGF mRNA. The resulting cell line (HTM-pSiCTGF) showed a significant $(P<0.02)$ 0.2-fold \pm 0.1 -fold reduction of mRNA for CTGF when compared with HTM-N cells (Figure 5A). The reduction in CTGF mRNA was associated with a substantial decrease in the amounts of CTGF and its target gene fibronectin, which were both barely detectable by Western blotting of proteins obtained from HTM-pSiCTGF cells (Figure 5B).

We next analyzed the structure of the actin cytoskeleton and the formation of focal contacts in HTM-N and HTM-pSiCTGF cells by labeling with phalloidin or antibodies against vinculin. When cells were seeded in culture dishes and kept there under serum free conditions for 24 hours, most HTM-N cells stretched and became spindle shaped (Figure 5C). By phalloidin labeling, a cortical actin cytoskeleton was observed and thin actin stress fibers were longitudinally arranged. Vinculin-la- beled focal contacts were mainly observed in the periphery of cells. In contrast, HTM-pSiCTGF cells did not stretch but remained roundish (Figure 5C). The phalloidin-labeled cortical actin cytoskeleton was larger than in HTM-N cells. In addition, the focal contacts at the cell periphery were broader and more intensely labeled for vinculin. When confluent areas of HTM-N or HTMpSiCTGF cells were stained for phalloidin and vinculin, HTM-N cells showed numerous thick and longitudinally arranged actin stress fibers that were associated with focal contacts and more intensely labeled than their cortical actin cytoskeleton (Figure 5D). In marked contrast, in HTM-pSiCTGF cells longitudinally arranged actin stress fibers were thin and barely detectable (Figure 5D). After treatment with $50 \mathrm{ng} / \mathrm{mL}$ of CTGF for 12 hours, the number and thickness of longitudinally arranged actin stress fibers markedly increased, and the actin cytoskeleton of 


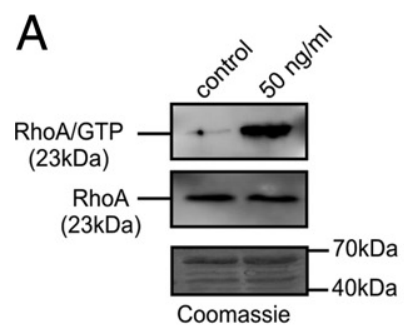

B

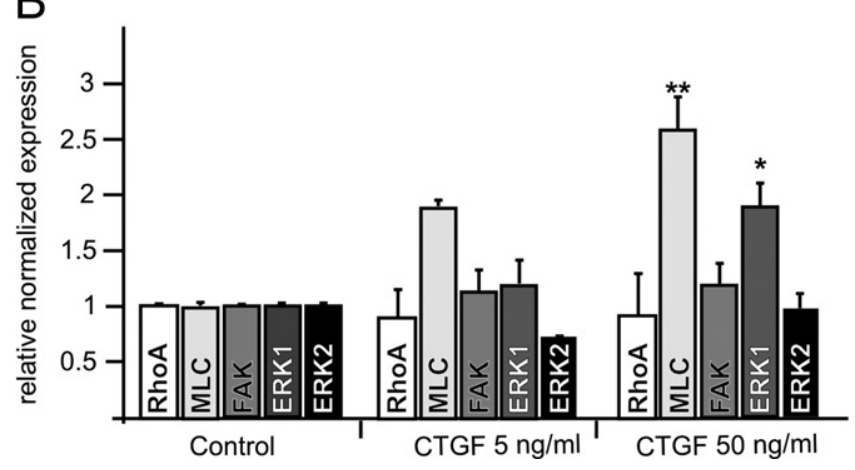

CTGF-treated HTM-pSiCTGF cells did not obviously differ from that of HTM-N cells (Figure 5D).

We next analyzed by Western blotting the amounts of $\alpha$-SMA and profilin 1 in confluent HTM-N and HTMpSiCTGF cells 24 hours after serum starvation. Profilin 1 promotes actin filament polymerization and is expressed constitutively throughout the body. A 0.57 -fold \pm 0.18 fold reduction was observed regarding the amounts of $\alpha$-SMA, whereas the amounts of profilin 1 were reduced by 0.3 -fold \pm 0.18 -fold when HTM-N cells were compared with HTM-pSiCTGF cells (Figure 5E). The changes correlated with a decrease in transcription, and a significant $(P<0.01)$ reduction of mRNA for $\alpha$-SMA $(0.74$ fold \pm 0.2 -fold) or profilin 1 (0.56-fold \pm 0.02 -fold) was observed by real-time RT-PCR of RNA from HTMpSiCTGF or HTM-N cells (Figure 5F). In contrast, no changes were detected regarding the amounts of $\alpha$ actinin (Figure 5E).

Next we analyzed activity or phosphorylation states of RhoA, MLCs, and FAK. In contrast to primary HTM cells, HTM-N cells showed distinct amounts of activated Rho/ GTP, which were significantly $(P<0.05)$ diminished by 0.26 -fold \pm 0.04 -fold in HTM-pSiCTGF cells (Figure $5 \mathrm{G}$ ). Moreover, we observed a 0.8 -fold \pm 0.13 -fold reduction in the amounts of pMLCs, whereas the number of total MLCs was increased by 2.5 -fold \pm 0.2 -fold (Figure $5 \mathrm{G}$ ). The amounts of pFAK were not obviously different between HTM-N and HTM-pSiCTGF cells, whereas total FAK was reduced by 0.57 -fold \pm 0.14 -fold in HTMpSiCTGF cells (Figure 5G).

\section{Transgenic Overexpression of CTGF in the Mouse Eye Causes Open-Angle Glaucoma}

Gene expression induced by adenoviral-mediated gene transfer is transient. ${ }^{56}$ To generate an animal model in which the tissues of the aqueous humor out-
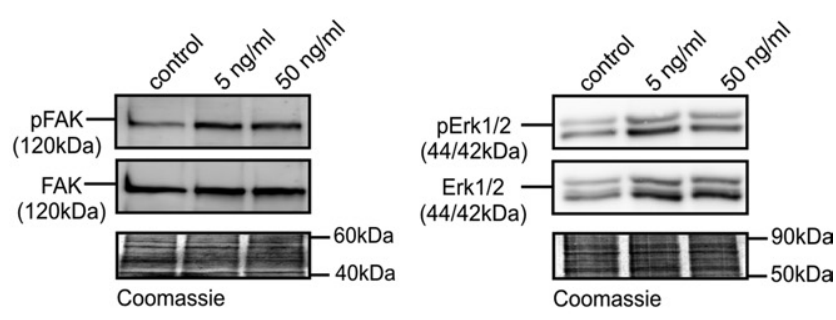

Figure 4. Signaling pathways induced by CTGF in cultured HTM cells. A Western blot analysis for RhoA/GTP and total RhoA, pMLCs and total MLCs, pFAK and total FAK, or pERK1/2 and total ERK1/2 in proteins of cultured HTM cells 3 hours after treatment with 5 or $50 \mathrm{ng} / \mathrm{mL}$ of CTGF. Coomassie blue staining to confirm equal loading of proteins. B: Quantitative real-time RT-PCR analysis for mRNA of RhoA, MLCs, FAK, ERK1, and ERK2 in total RNA from cultured HTM cells after 3 hours of treatment with 5 or $50 \mathrm{ng} / \mathrm{mL}$ of CTGF. The mean value obtained in untreated cells was set at 1 . GNB2L was used as reference gene $\left(n=4 ;{ }^{*} P<0.05,{ }^{* * *} P<0.02\right)$.

flow pathways are under the continuous influence of higher than normal amounts of CTGF, we next developed transgenic mice that overexpress CTGF in their lenses. We used the chicken $\beta \mathrm{B} 1$-crystallin promoter, which directs high and specific expression of transgenes to lens fibers of the mouse eye. ${ }^{44,57}$ A total of six independent transgenic lines were generated. Although lines with high transgenic expression showed developmental abnormalities of the ciliary body (data not shown), no obvious structural changes were observed in lines with moderate transgenic expression.

One of these lines, $\beta$ B1-CTGF1, was used for further analysis of the in vivo effects of continuously high amounts of CTGF on outflow tissues and IOP. Strong and specific expression of CTGF mRNA was seen in lenses of $\beta$ B1-CTGF1 animals but not in the rest of the eye or in lenses or eyes of WT littermates (Figure 6A). High expression in the transgenic lens caused secretion of high amounts of CTGF into the aqueous humor of transgenic animals (Figure 6B). In contrast, CTGF was not detectable in the aqueous humor of WT littermates. Light microscopy of the chamber angle of 1-month-old $\beta \mathrm{B} 1$ CTGF1 mice showed no obvious structural differences when compared with their WT littermates. In the eyes of both transgenic and WT animals, the chamber angle was wide open, and no obvious structural abnormalities were observed in ciliary body, iris, TM, and Schlemm's canal (Figure 6C). The same was true when the eyes of 2- or 3-month-old animals were investigated (not shown).

Differences were observed between transgenic and WT animals when the localization of CTGF in the anterior chamber angle was investigated by IHC. In the eyes of 2-month-old $\beta$ B1-CTGF1 mice, distinct immunoreactivity for CTGF was seen in the TM, in the corneal endothelium, and along the inner surface of the cornea (Figure 6D). In contrast, in the eyes of 2-month-old WT littermates, immunoreactivity in the TM was weak or absent (Figure 1D). 
A

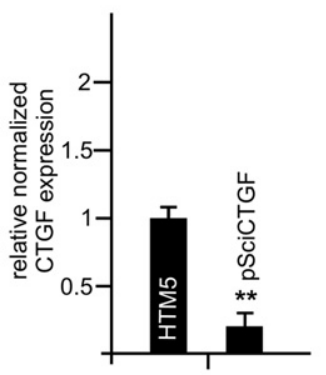

B
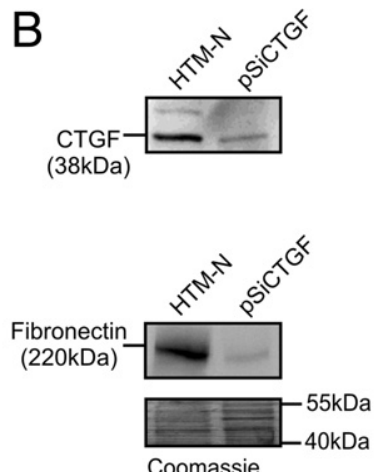

C

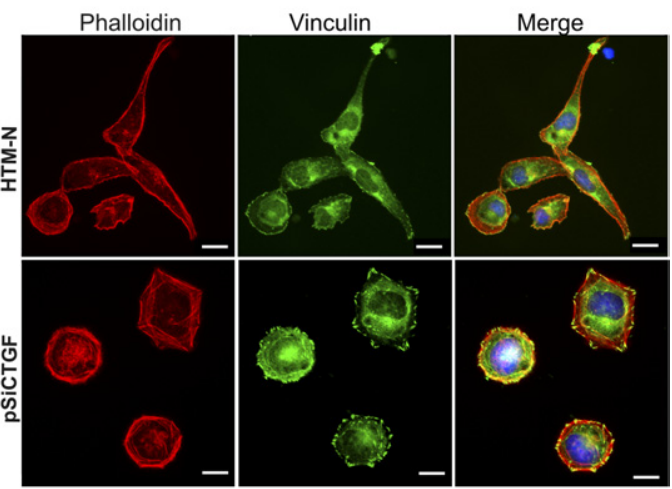

D
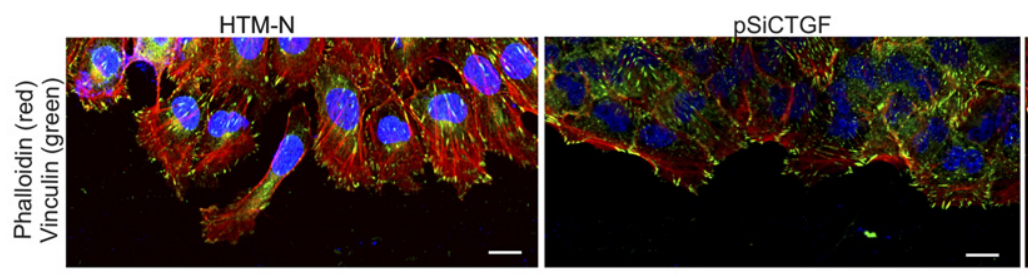

$\mathrm{pSiCTGF}+50 \mathrm{ng} / \mathrm{ml}$ CTGF

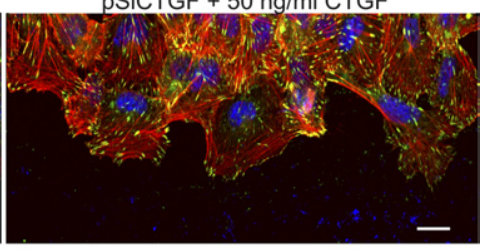

E

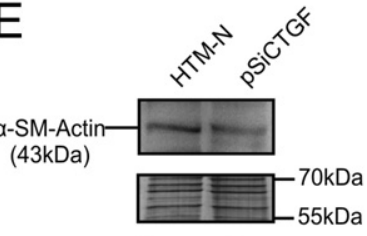

Coomassie

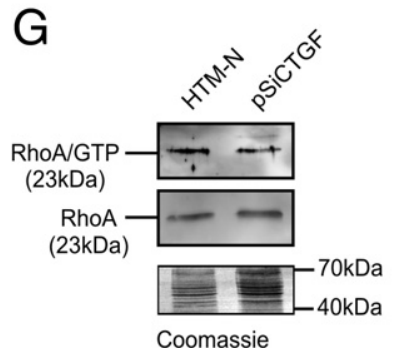

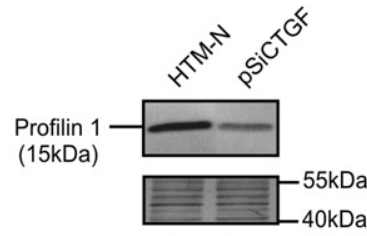

Coomassie

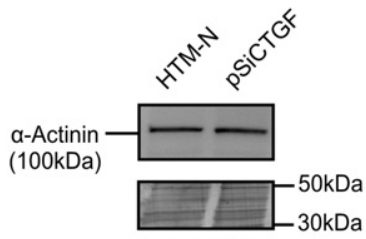

Coomassie

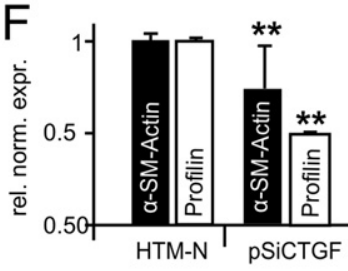

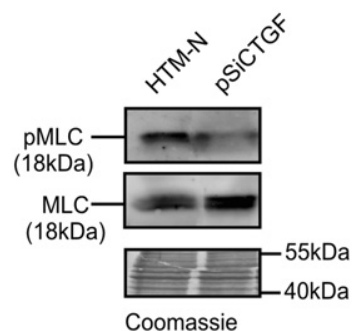

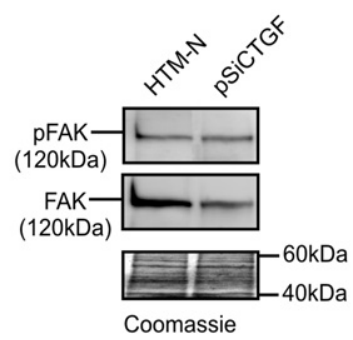

Figure 5. Depletion of CTGF in HTM cells by RNA interference attenuates the actin cytoskeleton. A: Real-time RT-PCR analysis for CTGF mRNA in HTM-N cells or HTM-pSiCTGF cells with stable depletion of CTGF. Mean value of HTM-N cells was set at 1 (** $P<0.02$, reference gene: GNB2L). B: Western blot analysis for CTGF or fibronectin in HTM-N or pSiCTGF cells; Coomassie blue staining was used to confirm equal loading of proteins. IHC for vinculin (green) and phalloidin labeling (red) of HTM-N or pSiCTGF cells 24 hours after seeding (C) or in confluent areas (D). In confluent areas, HTM-N cells show numerous thick and longitudinally arranged actin stress fibers that are associated with vinculin-labeled focal contacts. In marked contrast, in pSiCTGF cells longitudinally arranged actin stress fibers are barely detectable. After treatment of pSiCTGF cells with $50 \mathrm{ng} / \mathrm{mL}$ of CTGF for 12 hours, number and thickness of longitudinally arranged actin stress fibers significantly increases. E: Western blot analysis for $\alpha$-SMA, $\alpha$-actinin, or profilin-1 in HTM-N or pSiCTGF cells after serum starvation for 24 hours. F: Real-time RT-PCR analysis for mRNA of $\alpha$-SMA or profilin-1 in HTM-N or pSiCTGF cells after 24 hours. Mean value of HTM-N cells was set at 1 (** $P<0.02$; reference gene: GNB2L). G: Western blot analysis for RhoA/GTP and total RhoA, pMLCs and total MLCs, or pFAK and total FAK in HTM-N or pSiCTGF cells after serum free incubation for 3 hours. Coomassie blue staining was used to confirm equal loading of proteins.

In addition, marked changes were observed between transgenic and WT animals when the localization of fibronectin in the chamber angle was investigated. In the eyes of 2-month-old WT animals, immunoreactivity for fibronectin was seen immediately adjacent to the inner and outer walls of Schlemm's canal and close to the capillaries in the iris and ciliary body (Figure 6E). In contrast, in the eyes of 2-month-old $\beta$ B1-CTGF1 mice, immunoreactivity for fibronectin around Schlemm's canal and in the stroma of the ciliary body was considerably more intense (Figure 6E). In addition, 2-month-old $\beta \mathrm{B} 1$ CTGF1 mice showed intense immunoreactivity for $\alpha$-SMA in the TM and the stroma of the ciliary body (Figure 6F). In contrast, in the eyes of WT littermates, immunoreactivity for $\alpha$-SMA was mainly observed around ciliary body capillaries (Figure 6F).

We next measured IOP to learn whether transgenic overexpression of CTGF would cause an increase in IOP comparable to what we had observed for eyes with adenoviral-induced overexpression of CTGF. Eyes of 1-monthold WT littermates had a mean \pm SD IOP of $16.5 \pm 0.6$ $\mathrm{mm} \mathrm{Hg}(n=20)$, which was significantly $(P<0.05)$ lower than that measured in the eyes of $\beta$ B1-CTGF1 animals $(18.5 \pm 0.6 \mathrm{~mm} \mathrm{Hg}, n=15)$. The IOP of WT animals did 
A

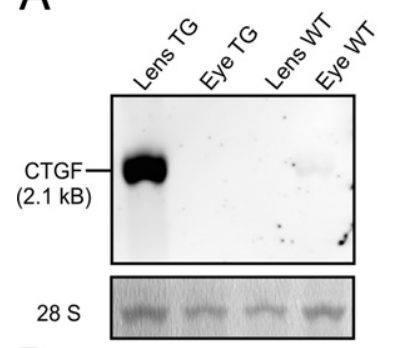

D

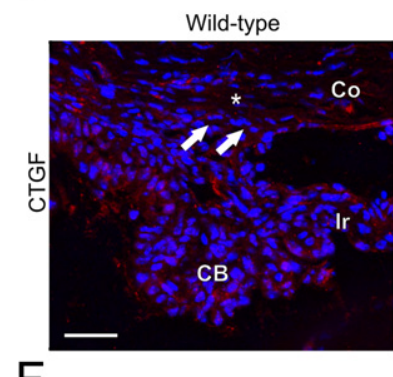

$\mathrm{F}$

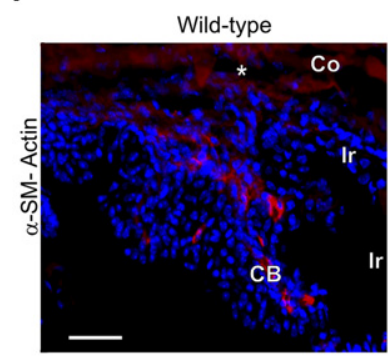

$\mathrm{H}$

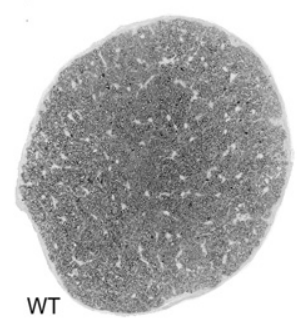

B

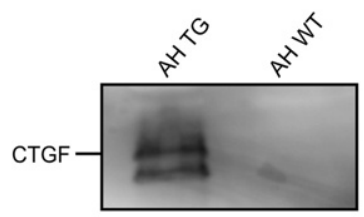

BB1-CTGF

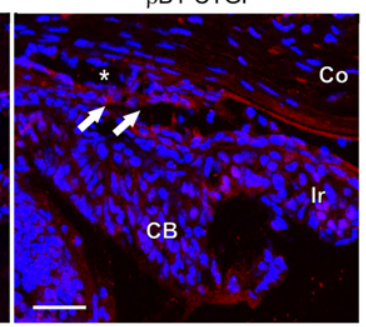

$\beta B 1-C T G F$
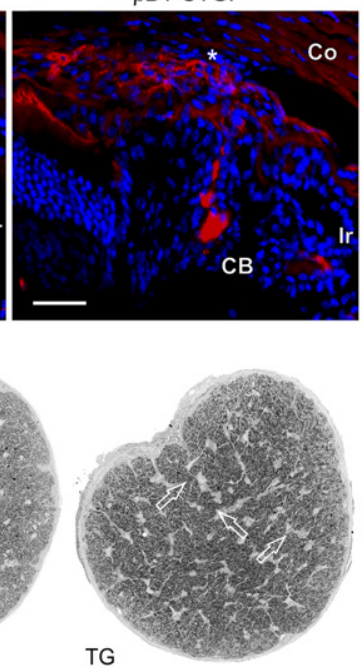

C

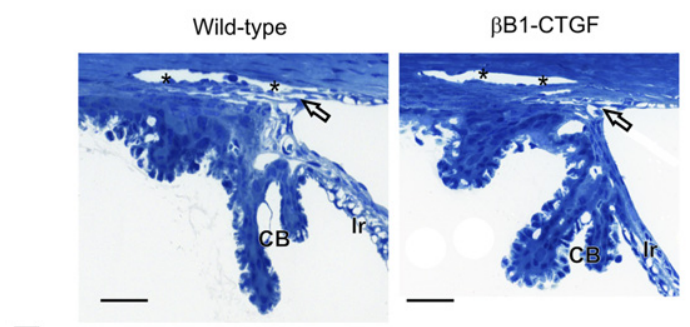

$E$
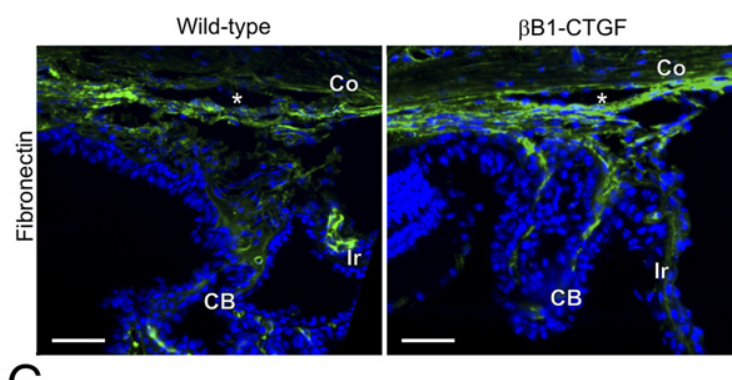

G
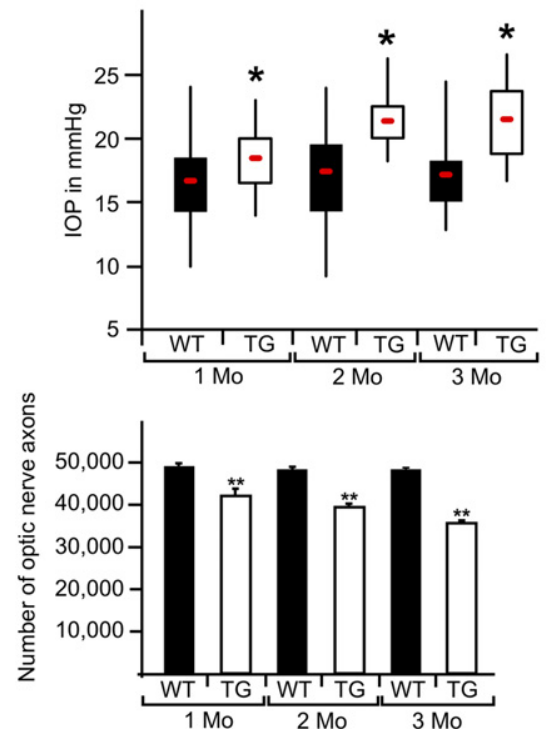

Figure 6. Analysis of CTGF overexpressing transgenic mice. A: Northern blot analysis for CTGF mRNA in transgenic and WT lenses and whole eyes without lenses. Methylene blue staining used to confirm equal loading. B: Western blot analysis for CTGF in aqueous humor of 1-month-old WT and transgenic $\beta$ B1-CTGF1 mice. C: Light microscopy. In WT and transgenic $\beta$ B1-CTGF1 mice, the iridocorneal angle is wide open, and no structural abnormalities are present in ciliary body (CB), iris (Ir), TM (arrow), and Schlemm's canal (SC, asterisks). D: IHC for CTGF in the anterior eye of 2-month-old WT and transgenic $\beta$ B1-CTGF1 mice. In the WT animal, immunoreactivity for CTGF in the TM is weak or absent (arrows). In contrast, in the transgenic $\beta$ B1-CTGF1 mouse immunoreactivity for CTGF is seen in the TM (arrows), in the corneal endothelium, and along the inner surface of the cornea. E: IHC for fibronectin in the iridocorneal angle of 2-month-old WT and transgenic $\beta$ B1-CTGF1 mice. In WT animals, fibronectin is seen adjacent to the SC and close to the capillaries in the Ir and CB. In contrast, in transgenic $\beta \mathrm{B} 1-\mathrm{CTGF} 1$ mice, immunoreactivity for fibronectin around the SC and in the stroma of the CB is more intense. F: IHC for $\alpha$-SMA in the iridocorneal angle of 2 -month-old WT and transgenic $\beta$ B1-CTGF1 mice. In transgenic $\beta$ B1-CTGF1 mice, intense immunoreactivity for $\alpha$-SMA is present in the TM and the stroma of the $\mathrm{CB}$ in contrast to the WT littermate. G: IOP measurement of 1 - to 3-month-old WT and transgenic $\beta$ B1-CTGF1 mice. Medians (red) with maximum and minimum (lines) and upper and lower quartile $\left(n \geq 15,{ }^{*} P<0.05\right)$. H: Optic nerve sections of 3 -month-old WT and transgenic $\beta$ B1-CTGF1 mice showing increased areas devoid of axons in transgenic $\beta$ B1-CTGF1 animals (left; arrows). Number of optic nerve axons in 1 - to 3-month-old WT and transgenic $\beta$ B1-CTGF1 mice (right; $\left.n=5 ;{ }^{* * *} P<0.01\right)$. Scale bars: $50 \mu \mathrm{m}(\mathbf{C}-\mathbf{F}) ; 20 \mu \mathrm{m}(\mathbf{H})$.

not significantly increase at $2(17.3 \pm 0.9, n=18)$ or 3 months of age $(17.1 \pm 0.3, n=14)$. In contrast, eyes of 2 or 3-month-old $\beta$ B1-CTGF1 animals had an IOP of $21.1 \pm$ $0.9 \mathrm{~mm} \mathrm{Hg}(n=17)$ or $22.2 \pm 1.2 \mathrm{~mm} \mathrm{Hg}(n=15)$, respectively, which was significantly higher $(P<0.05)$ than in WT littermates of the same age (Figure 6G).

Next we analyzed whether the increase in IOP would cause glaucomatous damage of the optic nerve. Histologic sections through optic nerves of 3-month-old WT and transgenic $\beta$ B1-CTGF mice showed considerable more areas devoid of axons in transgenic animals, indicating axonal loss. The areas were filled with cells of presumably glial nature (Figure $6 \mathrm{H}$ ). Next we quantitatively analyzed the number of optic nerve axons in $\beta \mathrm{B} 1$ CTGF1 animals and their WT littermates (Figure 6H). At 1 month of age, we measured 48,301 \pm 1332 axons in the optic nerves of WT animals and 41,023 \pm 2972 axons in optic nerves of $\beta$ B1-CTGF1 animals, a difference that 
A

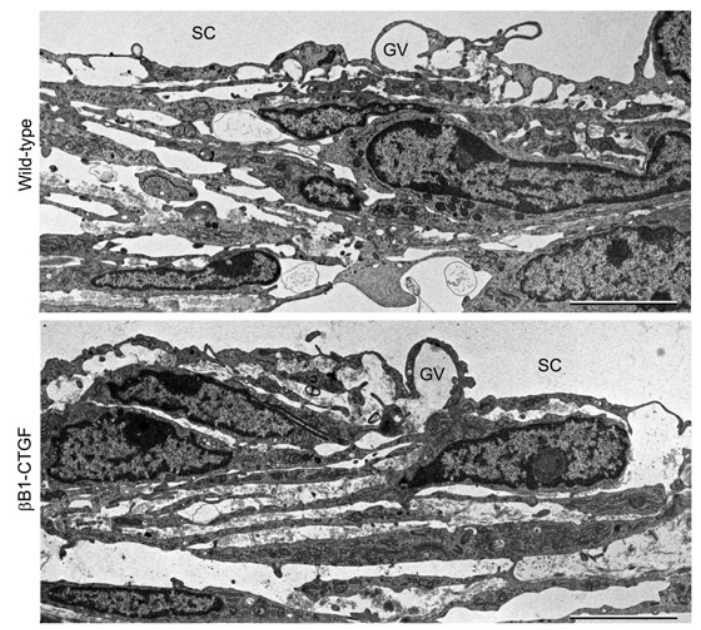

B

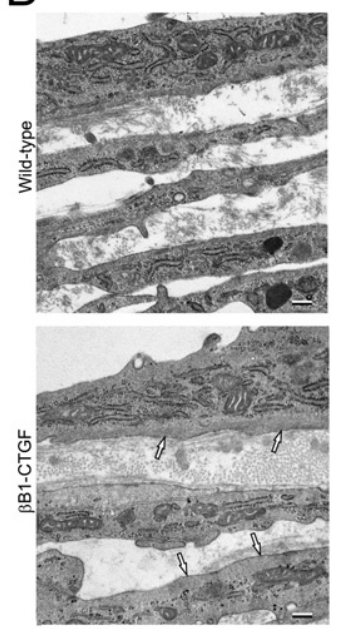

C

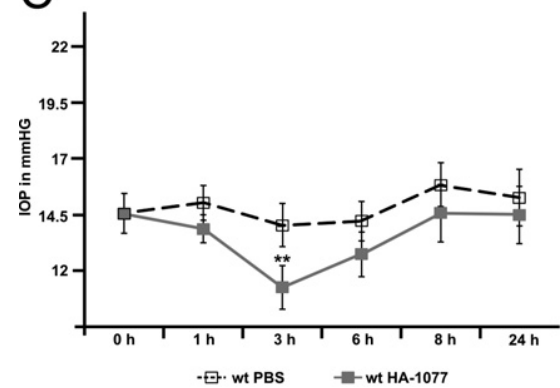

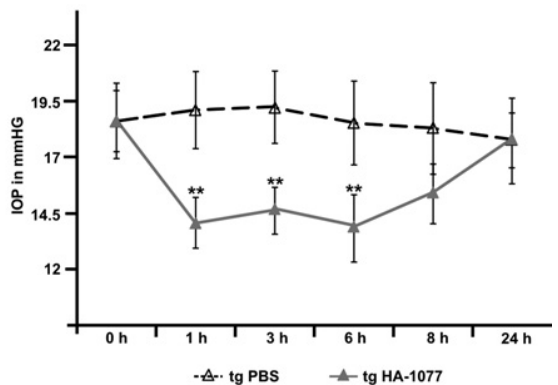

Figure 7. High IOP in $\beta$ B1-CTGF1 transgenic mice is associated with an increase in TM actin cytoskeleton. A: In the eyes of both $\beta$ B1CTGF1 mice and their WT littermates, TM cells are separated from each other by numerous optically empty spaces, whereas cells of Schlemm's canal (SC) endothelium form giant vacuoles (GVs). Scale bar $=2.5 \mu \mathrm{m}$. B: On higher magnification, a 150 - to $200-\mathrm{nm}$ broad area underneath the cell membrane that contains bundles of $6-$ to $7-\mathrm{nm}$ actin microfilaments is present in both $\beta$ B1-CTGF1 mice (arrows). In TM cells of WT littermates, bundles of 6- to 7-nm microfilaments are rarer and considerably thinner. Scale bar $=250 \mathrm{~nm}$. C: IOP measurement of 3-month-old WT and transgenic $\beta$ B1-CTGF1 mice after topical treatment with HA1077 (Fasudil) $\left({ }^{* * *} P<0.01\right)$. was statistically significant $(P<0.01)$. The loss of axons in optic nerves of $\beta$ B1-CTGF1 continued to increase with increasing age. Accordingly, 35,919 \pm 1826 axons where counted in optic nerves of 3 -month-old $\beta \mathrm{B} 1$ CTGF1 mice $(48,237 \pm 1248$ axons $)$, a $26 \%$ difference $(P<0.01)$ from the number of axons counted in WT littermates ( $n=5$, in each investigated stage and group), which clearly indicated continuous glaucomatous damage.

To analyze the causative mechanisms for the increased IOP in the eyes of $\beta$ B1-CTGF1 mice, we investigated the ultrastructure of the TM outflow pathways. In the eyes of both $\beta$ B1-CTGF1 mice and their WT littermates, TM cells were separated from each other by numerous optically empty spaces, whereas cells of Schlemm's canal endothelium frequently formed giant vacuoles (Figure 7A). On higher magnification, we regularly observed in TM cells of $\beta \mathrm{B} 1$ CTGF1 mice a 150- to 200-nm broad area underneath the cell membrane that contained bundles of 6- to 7-nm microfilaments corresponding to the diameter of actin filaments (Figure 7B). In TM cells of WT littermates, bundles of 6- to 7-nm microfilaments were more rarely observed and were considerably thinner (75 to 100 $\mathrm{nm}$ ) than those seen in transgenic eyes (Figure 7B).

Because the ultrastructural increase in TM actin filaments correlated with the increase in $\alpha$-SMA immunoreactivity, which we had observed by light microscopy, we wondered whether the increase in IOP in the eyes of $\beta$ B1-CTGF1 mice could be due to an increased contractility of the TM. Contraction of TM cells is known to increase TM outflow resistance, ${ }^{22,24}$ and disruption of TM actin stress fibers (eg, by Rho kinase inhibitors ${ }^{58,59}$ ) causes a reduction in outflow resistance. We, therefore, topically treated the eyes of 3 -month-old $\beta$ B1-CTGF1 mice and those of their WT littermates with the Rho kinase inhibitor HA1077, whereas contralateral eyes received PBS. PBS had no effect on IOP within 24 hours after administration (Figure $7 \mathrm{C}$ ) in either the eyes of WT littermates (0 hours: $17.1 \pm 0.9$; 1 hour: $17.5 \pm 0.8$; 3 hours: $16.5 \pm 1.0 ; 6$ hours: $16.8 \pm 0.9 ; 8$ hours: $18.3 \pm 1.0 ; 24$ hours: $17.7 \pm 1.2, n=10$ ) or in those of $\beta$ B1-CTGF1 mice (0 hours: $21.1 \pm 1.4 ; 1$ hour: $21.6 \pm 1.2$; 3 hours: $21.7 \pm$ 1.6; 6 hours: $21.1 \pm 0.8$; 8 hours: $20.8 \pm 1.1$; 24 hours: $20.3 \pm 1.2 ; n=11$ ). Three hours after the administration of HA1077 to the eyes of WT littermates, a significant $(P<0.01)$ reduction of IOP by $2.8 \mathrm{~mm} \mathrm{Hg}$ was observed $(13.8 \pm 1.0)$, which had almost returned to baseline 6 hours after treatment (Figure 7C). In contrast, when HA1077 was administered to the eyes of $\beta$ B1-CTGF1 mice a significant $(P<0.01)$ reduction of approximately $5.0 \mathrm{~mm} \mathrm{Hg}$ to $16.6 \pm 1.1 \mathrm{mmHg}$ was already observed 1 hour after treatment (Figure 7C). The reduction remained almost constant 3 hours (17.2 $\pm 1.0 \mathrm{~mm} \mathrm{Hg} ; \Delta 4.5 \mathrm{~mm} \mathrm{Hg}$ ) and 6 hours (16.4 \pm $1.2 \mathrm{~mm} \mathrm{Hg}, \Delta 4.6 \mathrm{~mm} \mathrm{Hg}$ ) after treatment and started to return to baseline after 8 hours. Overall, treatment with HA1077 almost completely reversed the increase in 
IOP in $\beta$ B1-CTGF1 mice to levels seen in untreated WT littermates.

\section{Discussion}

We conclude that high amounts of CTGF cause POAG in the mouse eye, an effect that is mediated by a CTGFinduced modification of the TM actin cytoskeleton. This conclusion rests on i) the observation that adenoviralmediated or transgenic overexpression of CTGF in the mouse eye causes an increase in IOP and a continuous decline in the number of optic nerve axons, ii) the absence of structural changes in TM and Schlemm's canal that would lead to closure of the iridocorneal angle, iii) the finding that CTGF overexpression causes an increase in the amounts of fibronectin and $\alpha$-SMA in the iridocorneal angle and of CTGF in the TM, iv) the potential of CTGF to induce actin stress fibers and contractility in cultured HTM cells, v) the observation that depletion of CTGF in cultured HTM cells causes a marked attenuation of the actin cytoskeleton, and vi) the capability of a Rho kinase inhibitor to cause a reversible decline in the IOP of CTGFoverexpressing transgenic mice to levels seen in control littermates.

The contractile properties of the TM and their role in modulating aqueous humor outflow resistance crucially depend on tone and integrity of the TM actin cytoskeleton. ${ }^{22-25}$ CTGF is expressed in high amounts in the human $\mathrm{TM}^{4}{ }^{42}$ and the findings of the present study indicate that it is critically required for increasing the contractile properties of the trabecular actin cytoskeleton. This molecular function appears not to be specific for TM cells but may be a general role of CTGF in cells of mesenchymal origin. Accordingly, CTGF signaling is capable of inducing actin stress fibers, integrin-mediated focal contacts, and activation of FAK in cultured fibroblasts. ${ }^{60,61}$ In contrast, embryonic fibroblasts isolated from CTGF-deficient mice show an impaired spreading on fibronectin, a delayed formation of actin stress fibers, and a reduced phosphorylation of ERK and FAK. ${ }^{62,63}$ Comparable results were obtained in CTGF-deficient chondrocytes that show reduced substrate adhesion and again diminished levels of ERK and FAK phosphorylation. ${ }^{64}$ More recently, we observed effects of CTGF in podocytes from the glomeruli of the kidney that are similar to those reported in the present study for TM cells. ${ }^{65}$ Treatment with CTGF increased the amount and density of podocyte actin stress fibers, the expression of a variety of actin-associated molecules, and the phosphorylation of FAK and ERK. Opposite effects were observed on depletion of CTGF. Similar to the cells of the TM, podocytes constitutively express CTGF and critically require the integrity of a submembranous actin cytoskeleton for their specific functional properties. ${ }^{66}$ CTGF may be the molecular switch that adjusts the actin cytoskeleton of mesenchymal cells that are continuously under mechanical load, such as TM cells, to their respective mechanical needs. In support of this, an increase in CTGF expression after an increase in mechanical load has been observed in cultured TM cells ${ }^{67}$ and in mul- tiple other cell types, such as fibroblasts, ${ }^{68-70}$ skeletal muscle ${ }^{71}$ chondrocytes, ${ }^{72}$ osteocytes, ${ }^{73}$ or mesangial cells of the kidney glomerulus. ${ }^{74,75}$

The expression of a specific actin isoform, $\alpha$-SMA, was found to be regulated by CTGF in cultured HTM cells, and overexpression of CTGF in the eye caused a marked increase in the number of cells in the iridocorneal angle that were labeled for $\alpha$-SMA. A comparable increase in the expression of $\alpha$-SMA typically occurs when fibroblasts differentiate to contractile myofibroblasts, such as during wound healing or in a variety of fibrotic diseases, such as pulmonary or liver fibrosis. ${ }^{76}$ The expression of $\alpha$-SMA in actin stress fibers confers to the differentiated myofibroblasts at least a twofold stronger contractile activity compared with $\alpha$-SMA-negative fibroblasts in culture. ${ }^{77}$ Myofibroblasts in fibrotic tissues or during wound healing form characteristic cell-matrix contacts or adhesion complexes that have been termed "fibronexus" and define the characteristic co-alignment of intracellular microfilament bundles with extracellular fibronectin fibrils at the surface of tissue myofibroblasts. ${ }^{78}$ By means of those adhesion complexes, intracellular forces are transmitted to extracellular fibrils. ${ }^{79}$ Similar cell matrix contacts have been described in scleral spur and posterior TM of the human eye ${ }^{80}$ and may well be present in the mouse TM, which shares essential structural characteristics with the human TM. ${ }^{81,82}$ The increase of fibronectin in the iridocorneal angle of eyes with transgenic or virus-induced CTGF overexpression that occurs in parallel to the increase of $\alpha$-SMA is consistent with this assumption. It is of interest that eyes with CTGF overexpression had higher than normal amounts of CTGF in the TM, strongly indicating that the presence of CTGF in this area is the causative factor for the increased amounts of fibronectin and $\alpha$-SMA.

It is reasonable to assume that elevated IOP in mouse eyes with CTGF overexpression is caused by molecular and/or structural changes in the TM outflow pathways. The changes do not involve closure of the iridocorneal angle (eg, due to iridocorneal adhesions) but occur in the presence of an open iridocorneal angle, a situation similar to POAG. In POAG, resistance to aqueous humor outflow is higher than normal in the TM outflow pathways, and a potential reason for this may be qualitative or quantitative changes of the TM extracellular matrix. ${ }^{17,34}$ By transmission electron microscopy, we did not find any evidence of a simple clogging of the TM outflow pathways by an excess in fibrillar extracellular matrix in eyes with CTGF overexpression. Still, some extracellular molecules, such as proteoglycans, which are potentially important for the generation of TM outflow resistance ${ }^{83}$ and may be regulated by CTGF, are difficult to visualize by this method and may have been lost during processing of the tissue. We found ultrastructural evidence though of an increase in actin microfilaments in TM cells of eyes with CTGF overexpression. Together with our observation that inhibition of Rho kinase caused a substantial and reversible decrease in IOP, the findings strongly argue for an increase in trabecular cellular tone or contractility as the major cause for the increase in IOP in CTGF-overexpressing mice. There is substantial evidence that con- 
traction of actin stress fibers is predominantly regulated by the activity of RhoA/Rho kinase, leading to a longlasting development of tensile force. ${ }^{84-86}$ In cultured HTM cells expressing a constitutively active form of RhoA (RhoAV14), a significant increase in the levels of fibronectin and $\alpha$-SMA was observed in association with increased actin stress fibers and MLC phosphorylation. ${ }^{87}$

An important aspect of our work is the fact that CTGFoverexpressing transgenic mice constitute a long sought rodent animal model ${ }^{88}$ with essential characteristics of POAG in humans. The most commonly used and best characterized mouse model, the DBA/2J mouse strain, is a model of secondary angle closure glaucoma. DBA/2J mice have mutations in 2 genes, Tyrp1 and Gpnmb, which lead to pigment dispersion, iris transillumination, iris atrophy, and anterior synechia. ${ }^{89}$ The changes lead to closure of the iridocorneal angle and block outflow of aqueous humor. Other mouse models are available for rare forms of open-angle glaucoma, such as glaucoma associated with mutations in myocilin, the most common genetically defined cause of glaucoma, responsible for approximately $4 \%$ of patients with POAG, ${ }^{90,91}$ or developmental forms of glaucoma that are associated with anterior segment dysgenesis. ${ }^{88}$ Mutant myocilin is not secreted into the aqueous humor but accumulates in the endoplasmic reticulum of the TM, thereby inducing endoplasmic reticulum stress and high IOP by a mechanism that is currently unclear. ${ }^{91} \mathrm{~A}$ clear advantage of CTGF-overexpressing transgenic mice over currently available rodent models is the fact that IOP can be modulated by substances (eg, Rho kinase inhibitors, which are also effective in human patients). ${ }^{92}$ CTGF-overexpressing transgenic mice have the potential to become an important tool to study molecular mechanisms of those types of medical glaucoma therapy that involve the outflow pathways of aqueous humor.

Higher than normal amounts of activated TGF- $\beta 2$ in the aqueous humor are present in approximately $50 \%$ of patients with POAG, a finding that has been independently observed in a variety of different laboratories worldwide. ${ }^{26-33}$ In cultured HTM cells, the expression of CTGF is highly up-regulated after treatment with TGF$\beta 2^{47}$ and may well be similarly up-regulated in the TM of human patients with POAG. Along this line, the structural and functional changes that are responsible for the increase in IOP in CTGF-overexpressing mice may similarly be involved in the increase in trabecular outflow resistance and high IOP in human patients. So far, no data are available that would indicate a stronger than normal contractility of the TM in eyes with POAG. Still, a recent study found evidence of an increase in TM stiffness in eyes with POAG, ${ }^{93}$ a finding that appears to be consistent with the concept of a glaucoma-related increase of the TM actin cytoskeleton and the extracellular fibrillar matrix that is associated with it. The amount of $\alpha$-SMA-positive TM cells was investigated in enucleated eyes with painful end-stage glaucoma, and a decrease in the number of such cells was found. ${ }^{94}$ Considering the fact that such eyes show substantial secondary changes, it would certainly be worthwhile to repeat those studies in eyes with early POAG. We are confident that a continuous investi- gation of the TM biology in the eyes of CTGF-overexpressing mice will provide further ideas and concepts that will help to unveil the pathogenesis of POAG.

\section{Acknowledgments}

We greatly appreciate the expert help of Margit Schimmel in transmission electron microscopy.

\section{References}

1. Resnikoff S, Pascolini D, Etya'ale D, Kocur I, Pararajasegaram R, Pokharel GP, Mariotti SP: Global data on visual impairment in the year 2002. Bull World Health Organ 2004, 82:844-851

2. Kwon YH, Fingert JH, Kuehn MH, Alward WL: Primary open-angle glaucoma. N Engl J Med 2009, 360:1113-1124

3. Quigley HA: Glaucoma. Lancet 2011, 377:1367-1377

4. Collaborative Normal-Tension Glaucoma Study Group: The effectiveness of intraocular pressure reduction in the treatment of normaltension glaucoma. Am J Ophthalmol 1998, 126:498-505

5. Collaborative Normal-Tension Glaucoma Study Group: Comparison of glaucomatous progression between untreated patients with normal-tension glaucoma and patients with therapeutically reduced intraocular pressures. Am J Ophthalmol 1998, 126:487-497

6. Gordon MO, Beiser JA, Brandt JD, Heuer DK, Higginbotham EJ, Johnson CA, Keltner JL, Miller JP, Parrish RK, 2nd, Wilson MR, Kass MA: The Ocular Hypertension Treatment Study: baseline factors that predict the onset of primary open-angle glaucoma. Arch Ophthalmol 2002, 120:714-730

7. Higginbotham EJ, Gordon MO, Beiser JA, Drake MV, Bennett GR, Wilson MR, Kass MA: The Ocular Hypertension Treatment Study: topical medication delays or prevents primary open-angle glaucoma in African American individuals. Arch Ophthalmol 2004, 122:813-820

8. Leske MC, Heijl A, Hussein M, Bengtsson B, Hyman L, Komaroff E: Factors for glaucoma progression and the effect of treatment: the early manifest glaucoma trial. Arch Ophthalmol 2003, 121:48-56

9. The AGIS Investigators: The advanced glaucoma intervention study (AGIS), 7: the relationship between control of intraocular pressure and visual field deterioration. Am J Ophthalmol 2000, 130:429-440

10. Anderson DR, Hendrickson A: Effect of intraocular pressure on rapid axoplasmic transport in monkey optic nerve. Invest Ophthalmol 1974, 13:771-783

11. Buckingham BP, Inman DM, Lambert W, Oglesby E, Calkins DJ, Steele MR, Vetter ML, Marsh-Armstrong N, Horner PJ: Progressive ganglion cell degeneration precedes neuronal loss in a mouse model of glaucoma. J Neurosci 2008, 28:2735-2744

12. Howell GR, Libby RT, Jakobs TC, Smith RS, Phalan FC, Barter JW, Barbay JM, Marchant JK, Mahesh N, Porciatti V, Whitmore AV Masland $\mathrm{RH}$, John SW: Axons of retinal ganglion cells are insulted in the optic nerve early in DBA/2J glaucoma. J Cell Biol 2007, 179:15231537

13. Tamm ER, Toris CB, Crowston JG, Sit A, Lim S, Lambrou G, Alm A: Basic science of intraocular pressure. Edited by Weinreb RN, Brandt JD, Garway-Heath D, Medeiros F. Amsterdam, Kugler Publications, 2007, pp 1-14

14. Tamm ER: The trabecular meshwork outflow pathways: structural and functional aspects. Exp Eye Res 2009, 88:648-655

15. Alm A, Nilsson SF: Uveoscleral outflow: a review. Exp Eye Res 2009, 88:760-768

16. Johnson M: 'What controls aqueous humour outflow resistance? Exp Eye Res 2006, 82:545-557

17. Tektas OY, Lütjen-Drecoll E: Structural changes of the trabecular meshwork in different kinds of glaucoma. Exp Eye Res 2009, 88:769775

18. Hann CR, Springett MJ, Wang X, Johnson DH: Ultrastructural localization of collagen IV, fibronectin, and laminin in the trabecular meshwork of normal and glaucomatous eyes. Ophthalmic Res 2001, 33: 314-324

19. Lütjen-Drecoll E, Rittig M, Rauterberg J, Jander R, Mollenhauer J: Immunomicroscopical study of type $\mathrm{VI}$ collagen in the trabecular 
meshwork of normal and glaucomatous eyes. Exp Eye Res 1989, 48:139-147

20. Lütjen-Drecoll E, Rohen JW: Functional morphology of the trabecular meshwork. Edited by Tasman W, Jaeger EA. Philadelphia, J.B. Lippincott Company, 2001, pp 1-30

21. Gottanka J, Johnson DH, Martus P, Lütjen-Drecoll E: Severity of optic nerve damage in eyes with POAG is correlated with changes in the trabecular meshwork. J Glaucoma 1997, 6:123-132

22. Tian B, Gabelt BT, Geiger B, Kaufman PL: The role of the actomyosin system in regulating trabecular fluid outflow. Exp Eye Res 2009, 88:713-717

23. Tian B, Geiger B, Epstein DL, Kaufman PL: Cytoskeletal involvement in the regulation of aqueous humor outflow. Invest Ophthalmol Vis Sci 2000, 41:619-623

24. Wiederholt M, Thieme $\mathrm{H}$, Stumpff $\mathrm{F}$ : The regulation of trabecular meshwork and ciliary muscle contractility. Prog Retin Eye Res 2000, 19:271-295

25. Rao VP, Epstein DL: Rho GTPase/Rho kinase inhibition as a novel target for the treatment of glaucoma. BioDrugs 2007, 21:167-177

26. Inatani M, Tanihara H, Katsuta H, Honjo M, Kido N, Honda Y: Transforming growth factor- $\beta 2$ levels in aqueous humor of glaucomatous eyes. Graefes Arch Clin Exp Ophthalmol 2001, 239:109-113

27. Min SH, Lee TI, Chung YS, Kim HK: Transforming growth factor-beta levels in human aqueous humor of glaucomatous, diabetic and uveitic eyes. Korean J Ophthalmol 2006, 20:162-165

28. Ochiai $\mathrm{Y}$, Ochiai $\mathrm{H}$ : Higher concentration of transforming growth factor-beta in aqueous humor of glaucomatous eyes and diabetic eyes. Jpn J Ophthalmol 2002, 46:249-253

29. Ozcan AA, Ozdemir N, Canataroglu A: The aqueous levels of TGFbeta2 in patients with glaucoma. Int Ophthalmol 2004, 25:19-22

30. Picht G, Welge-Luessen U, Grehn F, Lütjen-Drecoll E: Transforming growth factor- $\beta 2$ levels in the aqueous humor in different types of glaucoma and the relation to filtering bleb development. Graefes Arch Clin Exp Ophthalmol 2001, 239:199-207

31. Tripathi RC, Li J, Chan WFA, Tripathi BJ: Aqueous humor in glaucomatous eyes contains an increased level of TGF- $\beta 2$. Exp Eye Res 1994, 58:723-727

32. Trivedi RH, Nutaitis M, Vroman D, Crosson CE: Influence of race and age on aqueous humor levels of transforming growth factor-beta 2 in glaucomatous and nonglaucomatous eyes. J Ocul Pharmacol Ther 2011, 27:477-480

33. Yamamoto N, Itonaga K, Marunouchi T, Majima K: Concentration of transforming growth factor beta2 in aqueous humor. Ophthalmic Res 2005, 37:29-33

34. Lütjen-Drecoll E: Morphological changes in glaucomatous eyes and the role of TGFbeta2 for the pathogenesis of the disease. Exp Eye Res 2005, 81:1-4

35. Tamm ER, Fuchshofer R: What increases outflow resistance in primary open-angle glaucoma? Surv Ophthalmol 2007, 52(Suppl 2): S101-S104

36. Fuchshofer R, Tamm ER: Modulation of extracellular matrix turnover in the trabecular meshwork. Exp Eye Res 2009, 88:683-688

37. Nakamura Y, Hirano S, Suzuki K, Seki K, Sagara T, Nishida T: Signaling mechanism of TGF-beta1-induced collagen contraction mediated by bovine trabecular meshwork cells. Invest Ophthalmol Vis Sci 2002, 43:3465-3472

38. Tamm ER, Siegner A, Baur A, Lütjen-Drecoll E: Transforming growth factor- $\beta 1$ induces $\alpha$-smooth muscle-actin expression in cultured human and monkey trabecular meshwork. Exp Eye Res 1996, 62:389397

39. Junglas B, Yu AH, Welge-Lussen U, Tamm ER, Fuchshofer R: Connective tissue growth factor induces extracellular matrix deposition in human trabecular meshwork cells. Exp Eye Res 2009, 88:1065-1075

40. Ihn H: Pathogenesis of fibrosis: role of TGF- $\beta$ and CTGF. Curr Opin Rheumatol 2002, 14:681-685

41. Phanish MK, Winn SK, Dockrell ME: Connective tissue growth factor(CTGF. CCN2)-a marker, mediator and therapeutic target for renal fibrosis. Nephron Exp Nephrol 2009, 114:e83-e92

42. Tomarev SI, Wistow G, Raymond V, Dubois S, Malyukova I: Gene expression profile of the human trabecular meshwork: nElBank sequence tag analysis. Invest Ophthalmol Vis Sci 2003, 44:2588-2596

43. Kroeber M, Davis N, Holzmann S, Kritzenberger M, Shelah-Goraly M, Ofri R, Ashery-Padan R, Tamm ER: Reduced expression of Pax6 in lens and cornea of mutant mice leads to failure of chamber angle development and juvenile glaucoma. Hum Mol Genet 2010, 19:3332-3342

44. Ohlmann A, Scholz M, Goldwich A, Chauhan BK, Hudl K, Ohlmann AV, Zrenner E, Berger W, Cvekl A, Seeliger MW, Tamm ER: Ectopic norrin induces growth of ocular capillaries and restores normal retinal angiogenesis in Norrie disease mutant mice. J Neurosci 2005, 25 $1701-1710$

45. OhImann A, Seitz R, Braunger B, Seitz D, Bosl MR, Tamm ER: Norrin promotes vascular regrowth after oxygen-induced retinal vessel loss and suppresses retinopathy in mice. J Neurosci 2010, 30:183-193

46. Gimenez E, Montoliu L: A simple polymerase chain reaction assay for genotyping the retinal degeneration mutation (Pdeb(rd1)) in FVB/Nderived transgenic mice. Lab Anim 2001, 35:153-156

47. Fuchshofer R, Yu AH, Welge-Lüssen U, Tamm ER: Bone morphogenetic protein-7 is an antagonist of transforming growth factor-beta2 in human trabecular meshwork cells. Invest Ophthalmol Vis Sci 2007 , 48:715-726

48. Pang I-H, Shade DL, Clark AF, Steely HT, Desantis L: Preliminary characterization of a transformed cell strain derived from human trabecular meshwork. Curr Eye Res 1994, 13:51-63

49. Tamm ER, Russell P, Johnson DH, Piatigorsky J: Human and monkey trabecular meshwork accumulate alpha B-crystallin in response to heat shock and oxidative stress. Invest Ophthalmol Vis Sci 1996, 37:2402-2413

50. Vandesompele J, De Preter K, Pattyn F, Poppe B, Van Roy N, De Paepe A, Speleman F: Accurate normalization of real-time quantitative RT-PCR data by geometric averaging of multiple internal control genes. Genome Biol. 2002, 3:RESEARCH0034

51. Karnovsky MJ: A formaldehyde-glutaraldehyde fixative of high osmolality for use in electron-microscopy. J Cell Biol 1965, 27:137-138

52. Richardson KC, Jarret L, Finke H: Embedding in epoxy resins for ultrathin sectioning in electron microscopy. Stain Technol 1960, 35: 313-323

53. Schultze WH: Über das Paraphenylendiamin in der histologischen Färbetechnik und über eine neue Schnellfärbemethode der Nervenmarkscheide am Gefrierschnitt. Zentralbl Pathol 1972, 36:639-640

54. Jaffe AB, Hall A: Rho GTPases: biochemistry and biology. Annu Rev Cell Dev Biol 2005, 21:247-269

55. Ridley AJ, Hall A: The small GTP-binding protein rho regulates the assembly of focal adhesions and actin stress fibers in response to growth factors. Cell 1992, 70:389-399

56. Young LS, Searle PF, Onion D, Mautner V: Viral gene therapy strategies: from basic science to clinical application. J Pathol 2006, 208:299-318

57. Duncan MK, Li X, Ogino H, Yasuda K, Piatigorsky J: Developmental regulation of the chicken $\beta$ B1-crystallin promoter in transgenic mice. Mech Dev 1996, 57:79-89

58. Honjo M, Tanihara H, Inatani M, Kido N, Sawamura T, Yue BY, Narumiya S, Honda Y: Effects of rho-associated protein kinase inhibitor Y-27632 on intraocular pressure and outflow facility. Invest Ophthalmol Vis Sci 2001, 42:137-144

59. Rao PV, Deng PF, Kumar J, Epstein DL: Modulation of aqueous humor outflow facility by the Rho kinase-specific inhibitor Y-27632. Invest Ophthalmol Vis Sci 2001, 42:1029-1037

60. Chen CC, Chen N, Lau LF: The angiogenic factors Cyr61 and connective tissue growth factor induce adhesive signaling in primary human skin fibroblasts. J Biol Chem 2001, 276:10443-10452

61. Chen Y, Abraham DJ, Shi-Wen X, Pearson JD, Black CM, Lyons KM Leask A: CCN2 (connective tissue growth factor) promotes fibroblast adhesion to fibronectin. Mol Biol Cell 2004, 15:5635-5646

62. Kennedy L, Liu S, Shi-Wen X, Chen Y, Eastwood M, Sabetkar M, Carter DE, Lyons KM, Black CM, Abraham DJ, Leask A: CCN2 is necessary for the function of mouse embryonic fibroblasts. Exp Cell Res 2007, 313:952-964

63. Shi-wen X, Stanton LA, Kennedy L, Pala D, Chen Y, Howat SL, Renzoni EA, Carter DE, Bou-Gharios G, Stratton RJ, Pearson JD, Beier F, Lyons KM, Black CM, Abraham DJ, Leask A: CCN2 is necessary for adhesive responses to transforming growth factor-beta1 in embryonic fibroblasts. J Biol Chem 2006, 281:10715-10726

64. Nishida T, Kawaki H, Baxter RM, Deyoung RA, Takigawa M, Lyons KM: CCN2 (Connective Tissue Growth Factor) is essential for extracellular matrix production and integrin signaling in chondrocytes. J Cell Commun Signal 2007, 1:45-58 
65. Fuchshofer R, Ullmann S, Zeilbeck LF, Baumann M, Junglas B, Tamm ER: Connective tissue growth factor modulates podocyte actin cytoskeleton and extracellular matrix synthesis and is induced in podocytes upon injury. Histochem Cell Biol 2011, 136:301-319

66. Faul C, Asanuma K, Yanagida-Asanuma E, Kim K, Mundel P: Actin up: regulation of podocyte structure and function by components of the actin cytoskeleton. Trends Cell Biol 2007, 17:428-437

67. Chudgar SM, Deng P, Maddala R, Epstein DL, Rao PV: Regulation of connective tissue growth factor expression in the aqueous humor outflow pathway. Mol Vis 2006, 12:1117-1126

68. Kessler D, Dethlefsen S, Haase I, Plomann M, Hirche F, Krieg T, Eckes B: Fibroblasts in mechanically stressed collagen lattices assume a "synthetic" phenotype. J Biol Chem 2001, 276:36575-36585

69. Schild C, Trueb B: Mechanical stress is required for high-level expression of connective tissue growth factor. Exp Cell Res 2002 274:83-91

70. Schild C, Trueb B: Three members of the connective tissue growth factor family $\mathrm{CCN}$ are differentially regulated by mechanical stress. Biochim Biophys Acta 2004, 1691:33-40

71. Kivela R, Kyrolainen $H$, Selanne $H$, Komi PV, Kainulainen $H$, Vihko V: A single bout of exercise with high mechanical loading induces the expression of Cyr61/CCN1 and CTGF/CCN2 in human skeletal muscle. J Appl Physiol 2007, 103:1395-1401

72. Wong M, Siegrist M, Goodwin K: Cyclic tensile strain and cyclic hydrostatic pressure differentially regulate expression of hypertrophic markers in primary chondrocytes. Bone 2003, 33:685-693

73. Yamashiro T, Fukunaga $T$, Kobashi N, Kamioka $H$, Nakanishi $T$, Takigawa M, Takano-Yamamoto T: Mechanical stimulation induces CTGF expression in rat osteocytes. J Dent Res 2001, 80:461-465

74. Hishikawa K, Oemar BS, Nakaki T: Static pressure regulates connective tissue growth factor expression in human mesangial cells. J Biol Chem 2001, 276:16797-16803

75. Riser BL, Denichilo M, Cortes P, Baker C, Grondin JM, Yee J, Narins RG: Regulation of connective tissue growth factor activity in cultured rat mesangial cells and its expression in experimental diabetic glomerulosclerosis. J Am Soc Nephrol 2000, 11:25-38

76. Hinz B, Phan SH, Thannickal VJ, Galli A, Bochaton-Piallat ML, Gabbiani G: The myofibroblast: one function, multiple origins. Am J Pathol 2007, 170:1807-1816

77. Hinz B, Celetta G, Tomasek JJ, Gabbiani G, Chaponnier C: Alphasmooth muscle actin expression upregulates fibroblast contractile activity. Mol Biol Cell 2001, 12:2730-2741

78. Eyden B: The fibronexus in reactive and tumoral myofibroblasts: further characterisation by electron microscopy. Histol Histopathol 2001, 16:57-70

79. Hinz B, Gabbiani G: Mechanisms of force generation and transmission by myofibroblasts. Curr Opin Biotechnol 2003, 14:538-546
80. Tamm E, Flügel C, Stefani FH, Rohen JW: Contractile cells in the human scleral spur. Exp Eye Res 1992, 54:531-543

81. Smith RS, Zabaleta A, Savinova OV, John SW: The mouse anterior chamber angle and trabecular meshwork develop without cell death. BMC Dev Biol 2001, 1:3

82. Tamm ER, Kellenberger A: Aqueous humor dynamics and trabecular meshwork. Edited by Chalupa LM, Williams RW. Cambridge, MIT Press, 2008, pp 129-134

83. Keller KE, Aga M, Bradley JM, Kelley MJ, Acott TS: Extracellular matrix turnover and outflow resistance. Exp. Eye Res. 2009, 88:676682

84. Katoh K, Kano Y, Amano M, Onishi H, Kaibuchi K, Fujiwara K: Rhokinase-mediated contraction of isolated stress fibers. J Cell Biol 2001, 153:569-584

85. Katoh K, Kano Y, Noda Y: Rho-associated kinase-dependent contraction of stress fibres and the organization of focal adhesions. J R Soc Interface 2011, 8:305-311

86. Pellegrin S, Mellor H: Actin stress fibres. J Cell Sci 2007, 120:34913499

87. Pattabiraman PP, Rao PV: Mechanistic basis of Rho GTPase-induced extracellular matrix synthesis in trabecular meshwork cells. Am J Physiol Cell Physiol 2010, 298:C749-C763

88. Johnson TV, Tomarev SI: Rodent models of glaucoma. Brain Res Bull 2010, 81:349-358

89. Anderson MG, Smith RS, Hawes NL, Zabaleta A, Chang B, Wiggs JL, John SW: Mutations in genes encoding melanosomal proteins cause pigmentary glaucoma in DBA/2J mice. Nat Genet 2002, 30:81-85

90. Zhou Y, Grinchuk O, Tomarev SI: Transgenic mice expressing the Tyr437His mutant of human myocilin protein develop glaucoma. Invest Ophthalmol Vis Sci 2008, 49:1932-1939

91. Zode GS, Kuehn MH, Nishimura DY, Searby CC, Mohan K, Grozdanic SD, Bugge K, Anderson MG, Clark AF, Stone EM, Sheffield VC: Reduction of ER stress via a chemical chaperone prevents disease phenotypes in a mouse model of primary open angle glaucoma. $\mathrm{J}$ Clin Invest 2011, 121:3542-3553

92. Williams RD, Novack GD, Van Haarlem T, Kopczynski C: Ocular hypotensive effect of the rho kinase inhibitor AR-12286 in patients with glaucoma and ocular hypertension. Am J Ophthalmol 2011, 152:834-841

93. Last JA, Pan T, Ding Y, Reilly CM, Keller K, Acott TS, Fautsch MP, Murphy CJ, Russell P: Elastic modulus determination of normal and glaucomatous human trabecular meshwork. Invest Ophthalmol Vis Sci 2011, 52:2147-2152

94. Flügel C, Tamm E, Lütjen-Drecoll E, Stefani FH: Age-related loss of $\alpha$-smooth muscle actin in normal and glaucomatous human trabecular meshwork of different age groups. J Glaucoma 1992, 1:165-173 